\title{
The direct oxidative diene cyclization and related reactions in natural product synthesis
}

\author{
Juliane Adrian ${ }^{\ddagger}$, Leona J. Gross ${ }^{\ddagger}$ and Christian B. W. Stark ${ }^{*}$
}

\author{
Review \\ Address: \\ Fachbereich Chemie, Institut für Organische Chemie, Universität \\ Hamburg, Martin-Luther-King-Platz 6, 20146 Hamburg, Germany \\ Email: \\ Christian B. W. Stark ${ }^{*}$ - stark@chemie.uni-hamburg.de \\ * Corresponding author $\ddagger$ Equal contributors \\ Keywords: \\ asymmetric synthesis; natural products; oxidation catalysis; \\ tetrahydrofurans; total synthesis
}

\author{
Beilstein J. Org. Chem. 2016, 12, 2104-2123. \\ doi:10.3762/bjoc. 12.200 \\ Received: 04 June 2016 \\ Accepted: 07 September 2016 \\ Published: 30 September 2016 \\ This article is part of the Thematic Series "Natural products in synthesis \\ and biosynthesis II". \\ Guest Editor: J. S. Dickschat
}

(C) 2016 Adrian et al.; licensee Beilstein-Institut.

License and terms: see end of document.

\begin{abstract}
The direct oxidative cyclization of 1,5-dienes is a valuable synthetic method for the (dia)stereoselective preparation of substituted tetrahydrofurans. Closely related reactions start from 5,6-dihydroxy or 5-hydroxyalkenes to generate similar products in a mechanistically analogous manner. After a brief overview on the history of this group of transformations and a survey on mechanistic and stereochemical aspects, this review article provides a summary on applications in natural product synthesis. Moreover, current limitations and future directions in this area of chemistry are discussed.
\end{abstract}

\section{Introduction}

\section{Scope of this article}

After a concise introduction on the history and mechanistic aspects of the title reaction, the primary aim of the present review article is to summarize all relevant applications in natural product synthesis. The main text of this article is ordered by compound classes, so that tactics can easily be analysed and compared and similar applications can be condensed (both in the text and in the corresponding schemes). Methodology driven investigations as well as mechanistic studies are not the main focus of this review but may be mentioned in the introductory section. Likewise, syntheses of

fragments of natural products applying an oxidative cyclization protocol $[1,2]$ and sequential epoxidation/cyclization procedures [3] are not in the scope of this article and are therefore not covered. Previous review articles concerning oxidative diene cyclization chemistry can be considered in complement [4-6].

Oxidative cyclization - Historical background

In 1924 Kötz and Steche reported on an investigation of the constitution of the monoterpene geraniol $(\mathbf{1}, \mathrm{R}=\mathrm{H})$ [7]. Though the overall structure was known at that time, the position of one 
of the two $\mathrm{C}-\mathrm{C}$-double bonds within that natural product was in dispute (Scheme 1). Thus, the authors subjected a derivative (geranyl acetate $(\mathbf{1}, \mathrm{R}=\mathrm{Ac})$, Scheme 1$)$ to an aqueous solution of permanganate to dihydroxylate both double bonds in order to elucidate the structure. Elemental analysis of the crystalline reaction product ("Der reine Stoff bildet prächtige Krystalle ..." [7]) revealed that not one of the expected tetrols $\mathbf{2 a}$ or $\mathbf{2 b}$ (Scheme 1) but rather a cyclic anhydro compound seemed to be the result. Though a set of further reactions were carried out on this oxidation product, it proved not possible to establish its structure. It was not until 1965 when Klein and Rojahn at the flavours and fragrance company DRAGOCO (now Symrise AG) in Holzminden, northern Germany, reinvestigated the conversion of geranyl acetate $(\mathbf{1 b}, \mathrm{R}=\mathrm{Ac})$ with permanganate and were able to determine that the actual product is a 2,5bis(hydroxymethyl) THF (3 in Scheme 1, the general structure of which is today often as a simplification referred to as "THF diol") [8]. In addition, they found that this reaction proceeds with high stereoselectivity (vide infra) and demonstrated that the reaction is not only limited to terpenes such as geranyl- (1) $\mathrm{R}=\mathrm{Ac}$ ) or neryl acetate but seemed to be fairly general to other 1,5-diene substrates. Finally, they speculated on possible intermediates which may account for the outcome and the overall stereoselectivity of this unusual reaction. A mechanism, however, was not provided (vide infra).

To date it is firmly established that in addition to the permanganate-mediated reaction, both ruthenium- as well as osmium tetroxide mediate the same transformation (cf. Scheme 3) and that these reactions can, contrary to the original permanganatepromoted process, be run in a catalytic fashion. All published protocols using the three different $\mathrm{d}^{0}$-metals are highly diastereoselective (vide infra) and have been shown over the past decades to be applicable to a broad range of starting materials.

\section{Mechanistic aspects, stereochemistry and sub-} strate scope of the direct oxidative diene cyclization Intrigued by the unique chemistry reported by Klein and Rojahn [8], several research groups initiated programs in order to shed light on the stereochemical course and mechanism of what appeared to be a direct oxidative diene cyclization. After a controversial debate from the early years of the discovery until the 1980 s, it was finally broadly accepted that the overall reaction is a result of two consecutive syn-stereospecific [3+2]-oxidative cycloadditions (cf. type A mechanism; Scheme 3) [9-11]. Therefore, the double bond geometry of each of the two reacting double bonds translates directly to the relative stereochemistry of the vicinal hydroxy ether motif of the product (Scheme 2). The stereochemistry across the THF ring is set in the cyclization event. As a result of geometrical constraints it is usually predominantly or even exclusively cis (Scheme 2) -

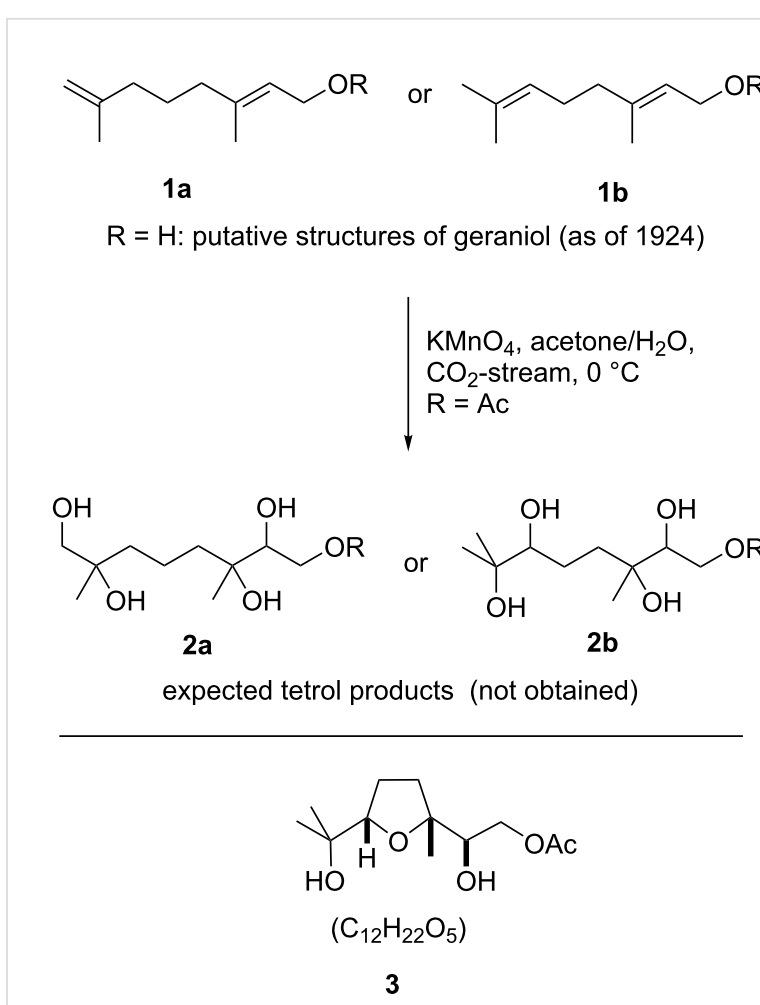

Scheme 1: Putative structures of geraniol $1 a(R=H)$ or $1 b(R=H)$ (in 1924), their expected dihydroxylation products $\mathbf{2 a}$ or $\mathbf{2 b}$ and the true structure 3 as determined by Klein and Rojahn in 1965 [8].

a fact that has recently been corroborated through density functional theory calculations both by Strassner and co-workers (Mn(VII) and Os(VIII)) [12,13] and by Kirchner and co-workers $(\mathrm{Ru}(\mathrm{VIII}))$ [14]. Reasonable fractions of the transTHF isomer can be produced using ruthenium tetroxide in specifically optimized solvent compositions [15] (for other means to obtain the trans-isomer from cis-THFs see the examples section below).

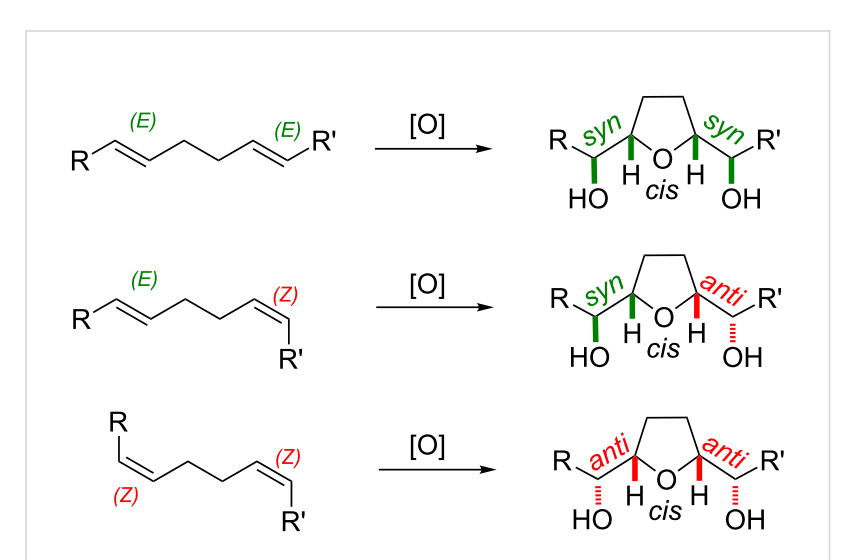

Scheme 2: Correlation between the substrate double bond geometry and relative stereochemistry of the corresponding THF diol products. 


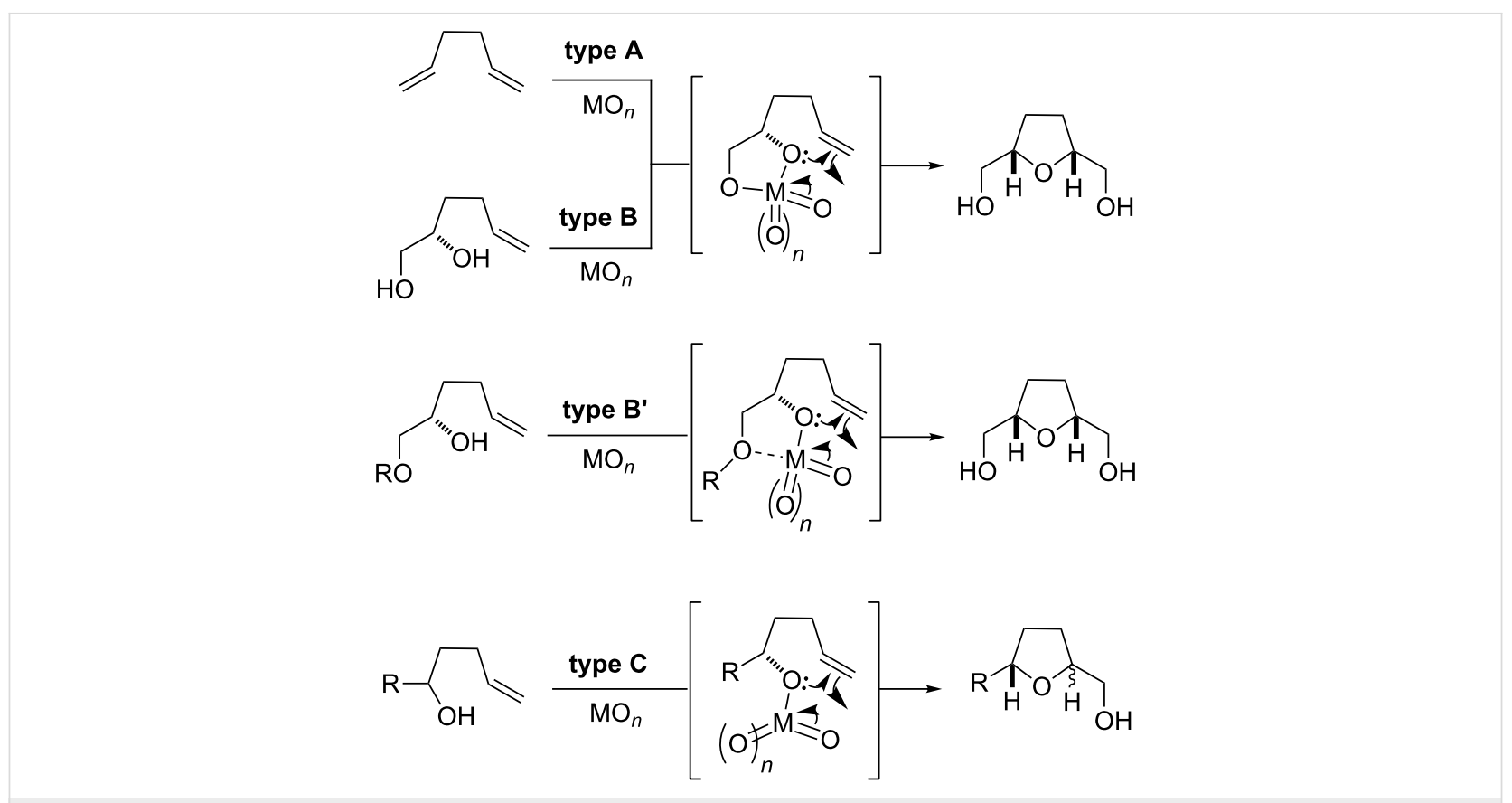

Scheme 3: Mechanisms and classification for the metal-mediated oxidative cyclizations to form 2,5-disubstituted THFs.

For all three procedures (using $\mathrm{Mn}(\mathrm{VII}), \mathrm{Ru}(\mathrm{VIII})$ and Os(VIII)) the scope of the reaction is very broad and a large number of 1,5-dienes with any kind of substitution pattern and double bond geometry have been used as substrates [4-6,16,17]. In addition, for Ru(VIII) [17-19] and Mn(VII) [21] it has been shown that also 1,6-dienes serve as substrates and can thus be directly converted to tetrahydropyrans [20-22]; ruthenium tetroxide even oxidizes 1,7-dienes to oxepans [23]. However, it has to be noted that the latter transformations do not have the same broad substrate spectrum as has been demonstrated for 1,5-diene precursors and there are no applications to natural product synthesis thus far.

A particularly fruitful extension of the direct 1,5-diene oxidation methodology (and due to mechanistic similarities also within the scope of this review) is the oxidative cyclization of 5,6-dihydroxyalkenes. This reaction has been reported to be catalyzed by Os(VI), Ru(VII) and $\mathrm{Cr}(\mathrm{VI})$ [24-26] and can be termed type B oxidative cyclization (as opposed to the direct oxidative cyclization of 1,5-dienes, referred to as type A reaction; cf. Scheme 3). In this case the diol and the metal oxide form a glycol ester intermediate which then undergoes an intramolecular oxidative addition to a remote double bond. Thereby, type B oxidative cyclizations converge to the same (or very similar) reactive intermediate as is passed through in type A reactions (Scheme 3). A relevant advantage of this approach is that enantiomerically pure products can be obtained when enantiomerically pure diol starting materials are used. A subgroup of closely related starting materials may contain an alkyl ether instead of a free hydroxy group at $\mathrm{C} 6(\mathrm{R} \neq \mathrm{H}$ in Scheme 3$)$. The key intermediate and cyclization precursor may then involve a coordinative bond of that ether oxygen to the strongly Lewis acidic metal center. Due to the close relation to type B cyclizations, they can be classified as type B' (Scheme 3). Reagents that mediate this type of reaction are $\mathrm{Re}(\mathrm{VII}), \mathrm{Cr}(\mathrm{VI})$ and $\mathrm{Co}(\mathrm{II})$ complexes [26-29]. Again, the observed efficiency and stereoselectivity for this class of oxidative cyclization reactions is high.

Another set of substrates are 5-hydroxyalkenes, starting materials, completely lacking the 6-OH-group (or ether oxygen donor). These compounds can only form mono-esters with the metal oxidant (Scheme 3). Therefore, they exhibit a different reactivity and a less ordered transition geometry in the oxygen transfer reaction and are thus categorized as a distinct class of oxidative cyclization, referred to as type $\mathrm{C}$ reaction. In fact, in these cases, mostly a trans-selectivity for the cyclization event is observed, due to the loose coordination. The most prominent oxidants to promote such type $\mathrm{C}$ reactions are $\mathrm{Co}(\mathrm{II})$ and $\mathrm{Re}$ (VII) complexes [27-29]. Reactions where a 5- and/or 6-(di)hydroxy group directs an oxidizing reagent to an internal alkene to form an epoxide followed by a subsequent cyclization are not covered in this article as these are different in mechanism since the oxidation and cyclization are two distinct events and do not occur in the same step [3].

The attraction to generate up to four chiral centers from a simple 1,5-diene precursor or up to two stereogenic centers 
when starting from 5,6- or 5-(di)hydroxyalkenes has progressively drawn the attention of synthetic organic chemists. These efforts have so far yielded some beautiful and persuasive results in the synthesis of natural products. The aim of the present review is to assemble key results of these applications and illustrate scope and limitations.

\section{Review}

\section{Oxidative cyclizations in the synthesis of carbohydrates, amino acids and polyketide natural products \\ (+)-Anhydro-D-glucitol and (+)-D-chitaric acid}

$(+)$-Anhydro-D-glucitol (6) was isolated from the mould fungus

Fusarium solani as a phytotoxin against barnyardgrass and duckweed in 1996 [30]. The Donohoe group presented a total synthesis in 2003 using an Os(VIII)-catalyzed oxidative cyclization as the key step [31] (Scheme 4). Several other total syntheses of that natural product did already exist or followed [3239].

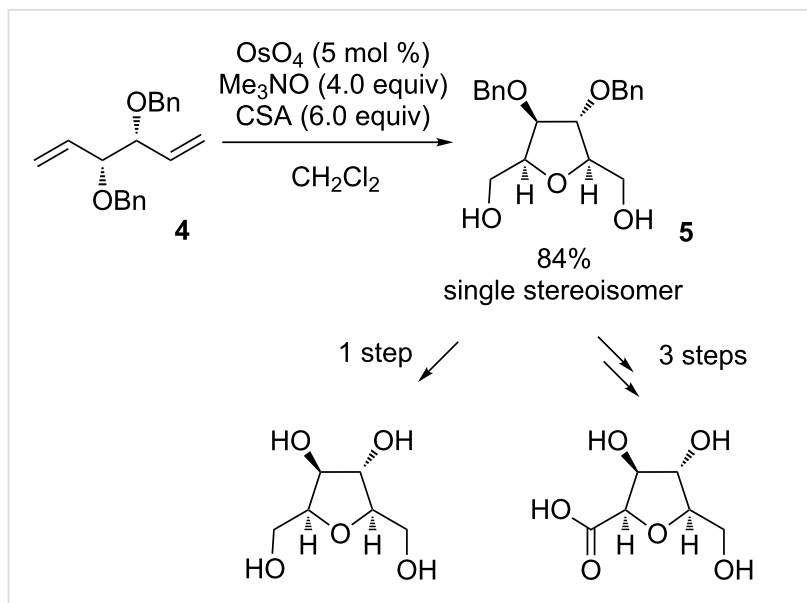

(+)-anhydro-D-glucitol (6) (+)-D-chitaric acid (7)

Scheme 4: Synthesis of (+)-anhydro-D-glucitol and (+)-D-chitaric acid using an $\mathrm{OsO}_{4}$-mediated oxidative cyclization.

Starting from the readily available $C_{2}$-symmetric 1,5 -diene 4 the 2,3,4,5-tetra-substituted THF diol $\mathbf{5}$ was obtained as a single stereoisomer with a yield of $84 \%$, following the type A cyclization. Deprotection led to natural (+)-anhydro-D-glucitol (6) (Scheme 4). It was also possible to produce another carbohydrate using the same synthetic pathway. Thus, mono-protection of THF diol 5 followed by oxidation of the remaining free primary hydroxy group to the carboxylic acid and a final hydrogenolysis gave (+)-D-chitaric acid (7) with a yield of $30 \%$ over three steps (Scheme 4). Additional to the synthesis of Donohoe described above [31], two other total syntheses of (+)-D-chitaric acid have been reported [40,41].

\section{Neodysiherbaine A}

In 2001, the excitatory amino acid neodysiherbaine A (14) has been found in the marine sponge Dysidea herbacea by Sakai et al. together with the already known and closely related dysiherbaine [42]. Neodysiherbaine A (14) is a neurologically active compound that acts as a glutamate receptor agonist and shows epileptogenic properties. Contiguous to the isolation, the first synthesis has been carried out by the same research group [42] and several other syntheses followed [43-47].

The Lygo group chose an approach using a Ru(VIII)-catalyzed type A oxidative cyclization to form the THF motif of the natural product (Scheme 5, left) $[48,49]$. Starting from diacetylL-arabinal (8), 1,5-diene 9 was obtained, which was subsequently cyclized. The reaction yielded the desired THF diol 10a in $61 \%$ as a single diastereoisomer together with over-oxidized 10b as side product. The total synthesis was finally achieved from 10a via some protecting group operations and an oxidation of the primary alcohol to the carboxylic acid [50,51].

In 2011, the Donohoe group developed a total synthesis of neodysiherbaine A (14) using an Os(VI)-catalyzed type B oxidative cyclization of a 5,6-dihydroxyalkene (Scheme 5, right) [52]. Commercially available $\beta$-D-ribopyranose tetraacetate (11) was converted to 12 via a Negishi coupling $[53,54]$. The oxidative cyclization diastereoselectively led to the THF diol $\mathbf{1 3}$ in $88 \%$ yield from which neodysiherbaine A (14) was obtained in a further three steps.

\section{Ionomycin}

Ionomycin (19), an ionophore antibiotic isolated from Streptomyces conglobatus in 1978 [55-57], has a high affinity for divalent cations. It is commonly used to both modify intracellular $\mathrm{Ca}^{2+}$ concentrations and to investigate $\mathrm{Ca}^{2+}$ transport across biological membranes [58]. In 2011, Kocienski and co-workers reported on a formal synthesis of ionomycin using an auxiliarydirected, diastereoselective permanganate-mediated oxidative cyclization to introduce the THF ring A and four of its stereogenic centers in a single step (Scheme 6) [59]. A related approach had previously been featured as a key step in their synthesis of salinomycin, a commercially significant coccidiostat [2].

The required $(Z, Z)$-diene $\mathbf{1 6}$ was prepared from commercially available neryl acetate (15). The auxiliary-controlled, permanganate-promoted oxidation of diene $\mathbf{1 6}$ proceeded selectively at low temperatures, affording the corresponding diastereomeric THF diols as an inseparable mixture (dr 7:1, major stereoisomer shown in Scheme 6). Compound 17 could successfully be converted into alcohol $\mathbf{1 8}$, an intermediate in the previously reported total synthesis of ionomycin (19) by Kocienski and 


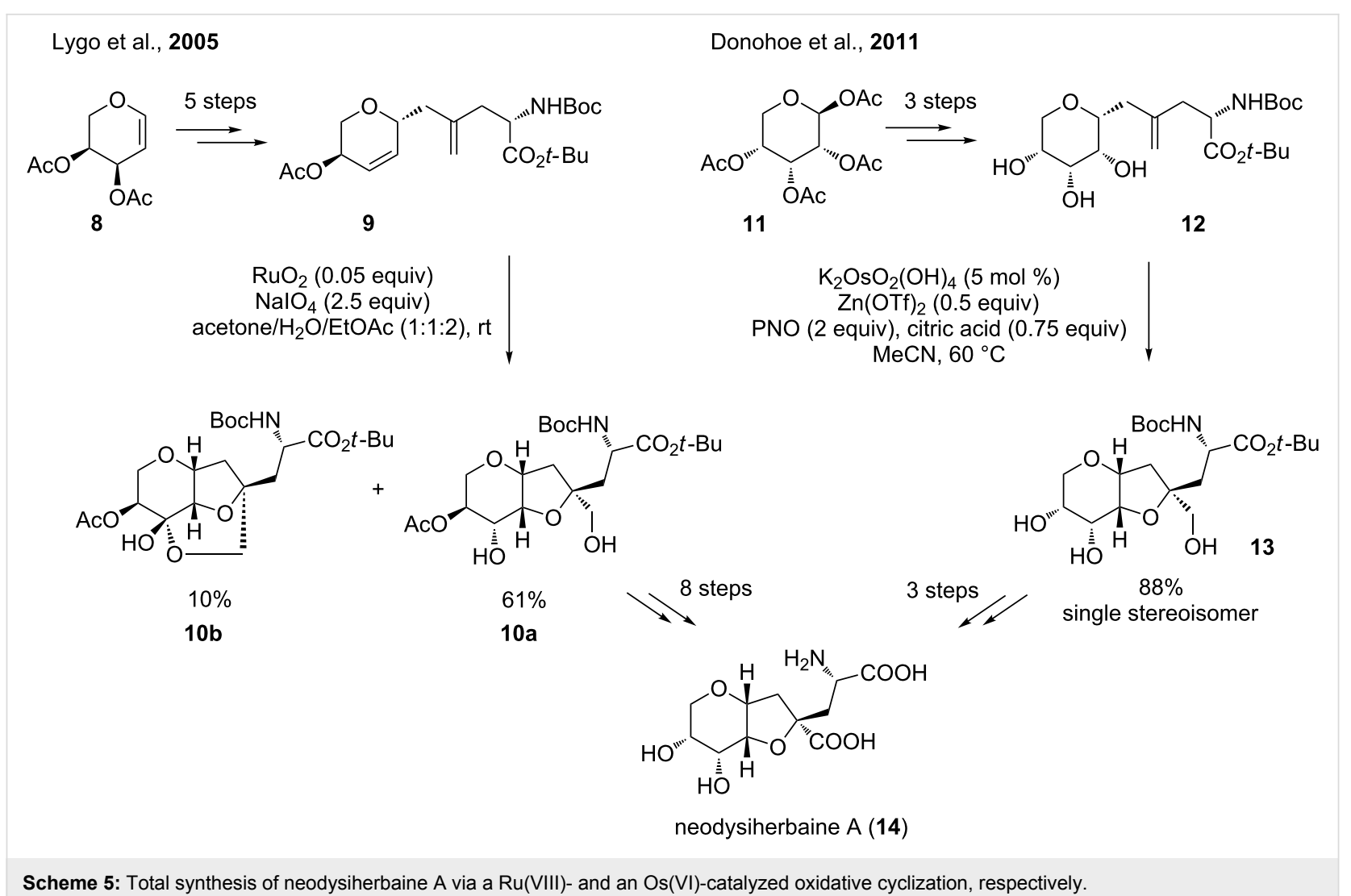<smiles>CC#CCCOC(C)=O</smiles>

15

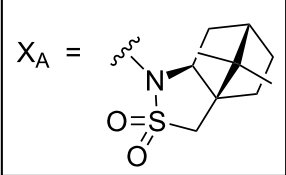

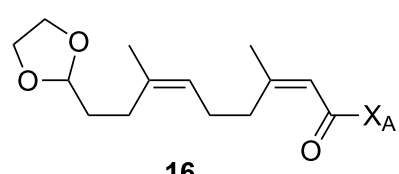

16

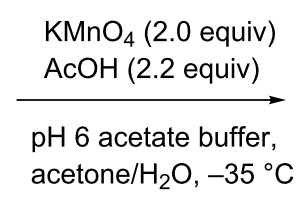

acetone $/ \mathrm{H}_{2} \mathrm{O},-35^{\circ} \mathrm{C}$
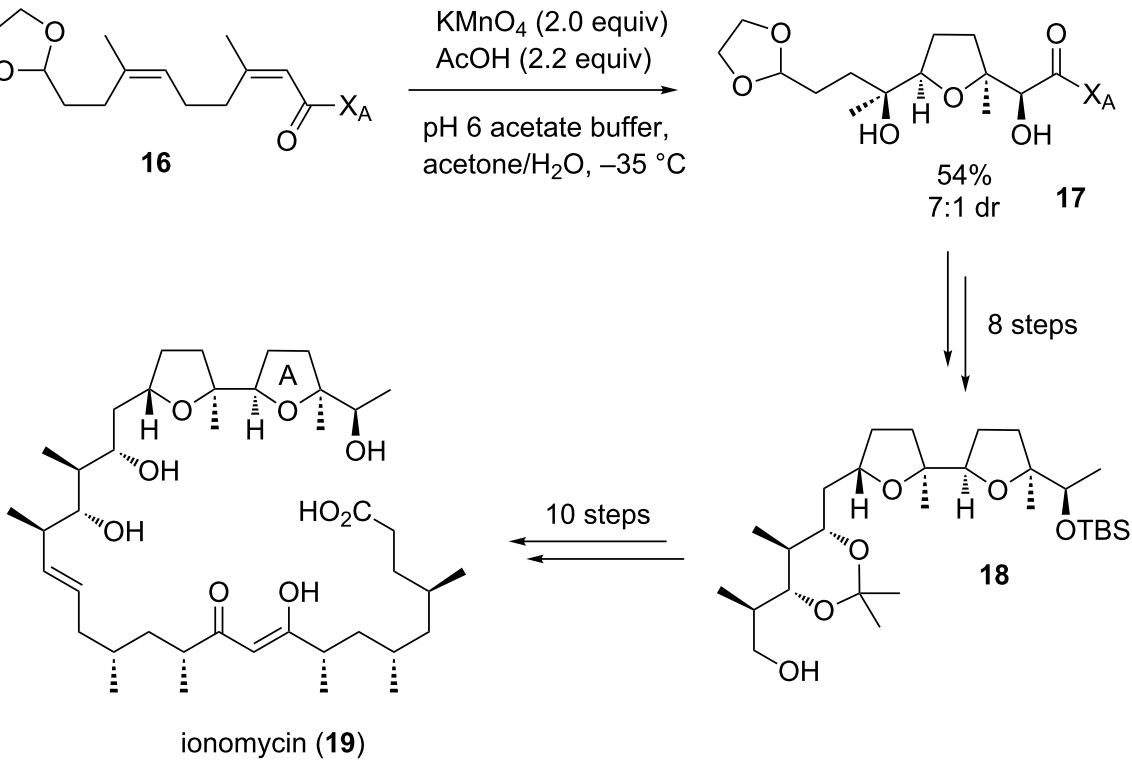

Scheme 6: Formal synthesis of ionomycin by Kocienski and co-workers.

co-workers [60] and also in the preceding syntheses developed by the group of Evans [61] and the Hanessian group [62], thus completing a formal synthesis of this polyketide. At this point it has to be mentioned that in 1987 the group of Weiler also used such a permanganate-promoted oxidative cyclization for the stereoselective synthesis of the THF unit in ionomycin [63]. Similarly, in 1980 Walba et al. reported on the B/C-ring fragment synthesis of monensin A, another well-known ionophore 
antibiotic, applying an oxidative cyclization approach using potassium permanganate [64].

\section{Amphidinolide F}

Amphidinolide F (24) is a marine natural product isolated from the dinoflagellate Amphidinium sp. in 1991 [65]. The macrocyclic core of these highly cytotoxic secondary metabolites contains two 2,5-trans-substituted THF ring systems (Scheme 7) [66,67]. Despite significant efforts from various research groups, it took more than two decades from its isolation and characterization to the publication of its first total synthesis by Carter and co-workers in 2012 [67,68].

In 2013, the Fürstner group published a successful approach to amphidinolide F (24) applying an oxidative type C Mukaiyama cyclization reaction for the THF segment 22 (Scheme 7) $[69,70]$. Therefore, enantiomerically pure epoxide 20 was converted to 5 -hydroxyalkene $\mathbf{2 1}$, the oxidative cyclization precursor in this total synthesis. The subsequent cobalt-catalyzed cyclization reaction proceeded chemoselectively in the presence of the alkyne moiety and provided the trans-disubstituted THF 22 in high yield [69-71]. Finally, building block 23, one important fragment in the total synthesis of amphidinolide $\mathrm{F}$ (24), was accessible in good overall yield and high diastereoselectivity $(\mathrm{dr} \approx 95: 5)$ in only four steps (Scheme 7).

\section{Oxidative cyclizations in the synthesis of annonaceous acetogenins cis-Solamin A}

cis-Solamin represents a typical mono-THF acetogenin, originally isolated from the roots of the tropical fruit tree Annona muricata in 1998 [72]. The relative stereochemistry within the THF diol core was assigned as threo-cis-threo, whereas the absolute configuration present in cis-solamin was not estab- lished at the time of isolation. Then in 2006, the groups of Figadère and Brown were able to show that natural cis-solamin actually occurs as a mixture of two tetra-epimeric diastereoisomers cis-solamin A (29, Scheme 8) and cis-solamin B [73]. It therefore has to be noted that structure $\mathbf{2 9}$ was referred to as "cis-solamin" in the literature, up to that important discovery by Figadère and Brown. Its diverse biological activities [72] together with its broadly unexplored biogenesis $[73,74]$ motivated many synthetic groups to develop total syntheses of cissolamin A (29) [75-83] and B [76,78,83].

In 2002, Brown and co-workers achieved concise total syntheses of cis-solamin A (29) and B using the diastereoselective, auxiliary-controlled, permanganate-promoted type A oxidative cyclization of 1,5-dienes to create the THF diol backbone and to introduce four of the five stereogenic centers present in these mono-THF acetogenins (left, Scheme 8) [76,78]. Starting from commercially available aldehyde $\mathbf{2 5}$, diene $\mathbf{2 7}$ was obtained in few steps and subsequently cyclized. Previously established standard conditions using acetone-water delivered THF-diol 28a in only $18 \%$ yield. Better results were achieved when the oxidative cyclization was carried out under phase-transfer conditions [84]. Thus, the corresponding THF diols were obtained in 55\% yield. In addition to the desired THF diol 28a for the total synthesis of cis-solamin A (29), small amounts of its diastereoisomer $\mathbf{2 8 b}$ were isolated (dr 10:1, Scheme 8 left). Similar permanganate-mediated oxidative cyclizations were also successfully applied to the total syntheses of two more mono-THF acetogenins, cis-uvariamicin I and cis-reticulatacin, by the Brown group [85].

A formal synthesis of cis-solamin A (29) was published in 2005 by the Donohoe group, employing their Os(VI)-catalyzed oxidative cyclization of 5,6-dihydroxyalkenes as the key step<smiles>[Z12]CC[C@H](O)CC#CC</smiles>

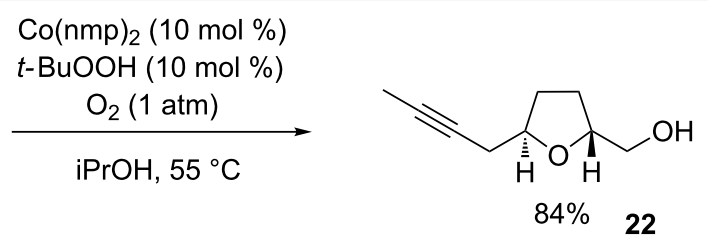

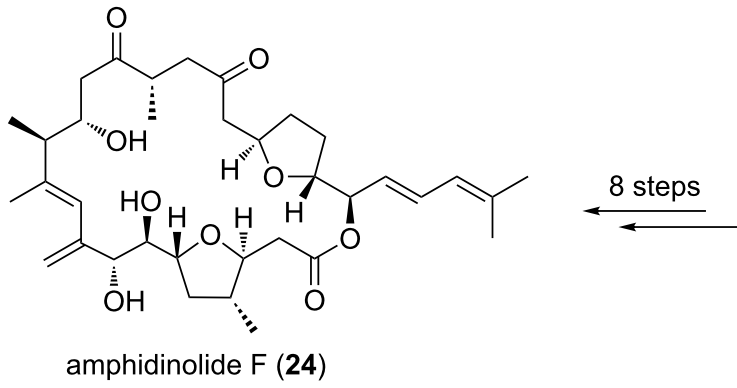

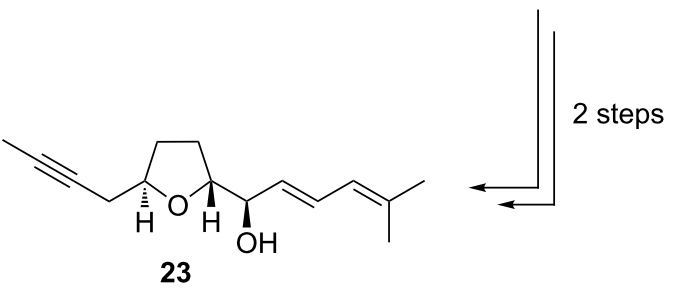




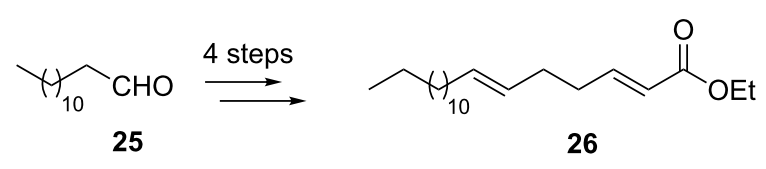

\section{Brown et al., 2002}
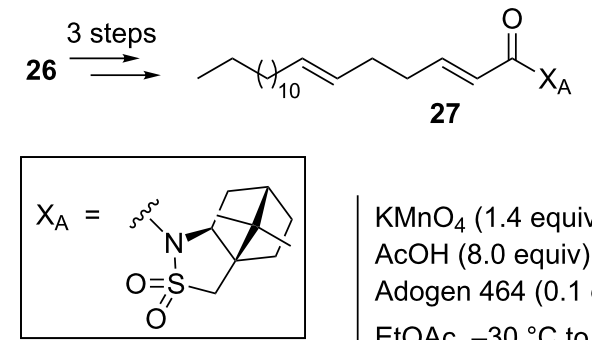

$\mathrm{KMnO}_{4}$ (1.4 equiv) $\mathrm{AcOH}$ (8.0 equiv) Adogen 464 ( 0.1 equiv) EtOAc, $-30^{\circ} \mathrm{C}$ to $0^{\circ} \mathrm{C}$<smiles>[Y4]C(=O)C(O)C1CCC([18OH])([C@H](O)C[Y20]C)O1</smiles>

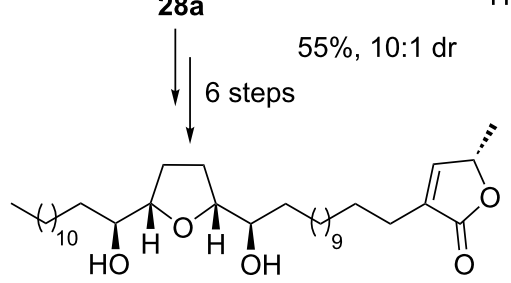

(+)-cis-Solamin A (29)
Donohoe et al., 2005

$26 \stackrel{\text { DIBAL-H }}{\longrightarrow}$<smiles>CCCCCCCC=CCO</smiles>

$86 \%$ from $26,>90 \%$ ee

$\mathrm{OsO}_{4}(5 \mathrm{~mol} \%)$

$\mathrm{Me}_{3} \mathrm{NO}$ (4.0 equiv), TFA (6.0 equiv) isoprene (5.0 equiv) acetone $/ \mathrm{H}_{2} \mathrm{O}$, rt

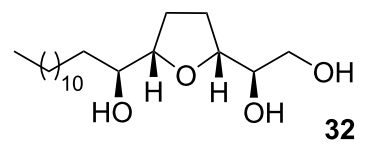

$81 \%,>90 \%$ ee

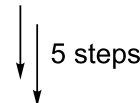

(+)-cis-solamin A (29)

Scheme 8: Brown`s and Donohoe`s oxidative cyclization approach to cis-solamin A.

(right, Scheme 8) [79]. After reduction of the ester 26, a Sharpless asymmetric dihydroxylation (AD) [86-88] reaction furnished diol 31 with a high degree of both regio- and enantioselectivity. Osmium-promoted oxidative type B cyclization of 31 proceeded in high yield (81\%) and with high stereoselectivity (ee $>90 \%$ ) to give THF diol 32. The latter could be almost quantitatively converted to the corresponding tosylate, an intermediate in Brown's synthesis of cis-solamin A (29) [76,78], thus completing a formal synthesis of this natural product (Scheme 8).

In 2006, our group succeeded in synthesizing cis-solamin A (29) utilizing a ruthenium tetroxide-catalyzed type A oxidative cyclization approach (Scheme 9) [80]. Silyl-protected dienediol 34, the oxidative cyclization precursor, was synthesized from all-trans-cyclododecatriene $\mathbf{3 3}$ in four steps including dihydroxylation, glycol cleavage [89], subsequent borohydride reduction and protection of the resulting diol. The Ru(VIII)-catalyzed oxidative cyclization in the presence of sodium periodate on wet silica [90] as the oxidizing agent delivered the THF diol 35 in high yield (83\%). The product was formed with excellent diastereocontrol ( $d r>98: 2)$. Subsequent enzymatic desymmetrization [91] using lipase Amano AK gave the enantiomerically pure acetate 36 in $81 \%$ yield (ee $>99 \%$ ). A further three transformations then delivered cis-solamin A (29). Crucial to the success of this approach and its high efficiency is that it takes advantage of the meso-geometry of the central THF diol moiety [80].

\section{cis-Sylvaticin}

cis-Sylvaticin (40), a non-adjacent bis-THF acetogenin [92] (Scheme 10), was discovered in dried fruits of Rollinia sylvatica [93] and leafs of Rollinia mucosa [94]. It has been shown to be cytotoxic against several cancer cell lines at nanomolar concentrations $[93,94]$. Two different synthetic approaches to cissylvaticin (40) were reported, utilizing an oxidative cyclization to stereoselectively establish the cis-configured 2,5-disubstituted THF rings.

The first total synthesis of cis-sylvaticin (40) has been accomplished in 2006 by the Donohoe group, using an osmium-catalyzed double type B oxidative cyclization strategy (Scheme 10) 


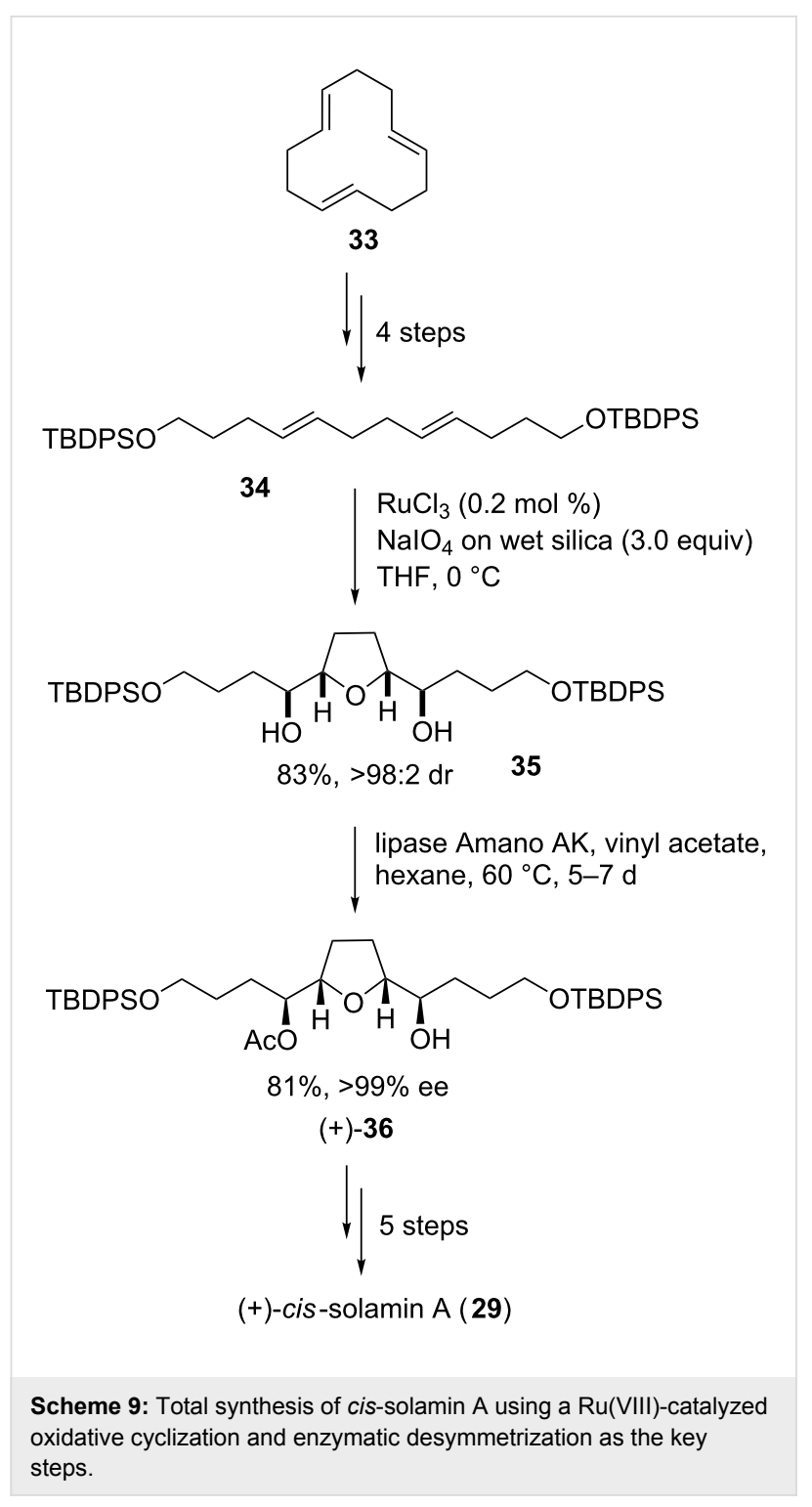

$[5,95]$. The protected precursor $\mathbf{3 8}$ was synthesized from tetraene $\mathbf{3 7}$ in five steps involving a highly position- and stereoselective Sharpless AD reaction [86-88] (ee $>98 \%$, de $>90 \%$ for the all $s y n$-isomer). Subsequent osmium tetroxide-catalyzed oxidative cyclization under acidic reaction conditions resulted in bis-THF 39 which was isolated in $77 \%$ yield and as a single diastereoisomer. Thus, both THF rings of the natural product were established at the same time (Scheme 10) [5,95]. Based on this approach, in 2009, Donohoe and co-workers also reported the first total synthesis of (+)-sylvaticin [92,96], the C12-epimer of cis-sylvaticin (40) using oxidative cyclization chemistry to establish both the 2,5-cis- and the 2,5-trans-substituted THF ring of the natural product. However, it has to be noted that the trans-THF was not directly formed in an oxidative cyclization reaction but rather through a subsequent sequential solvolysis/ hydride shift/intramolecular reduction cascade.

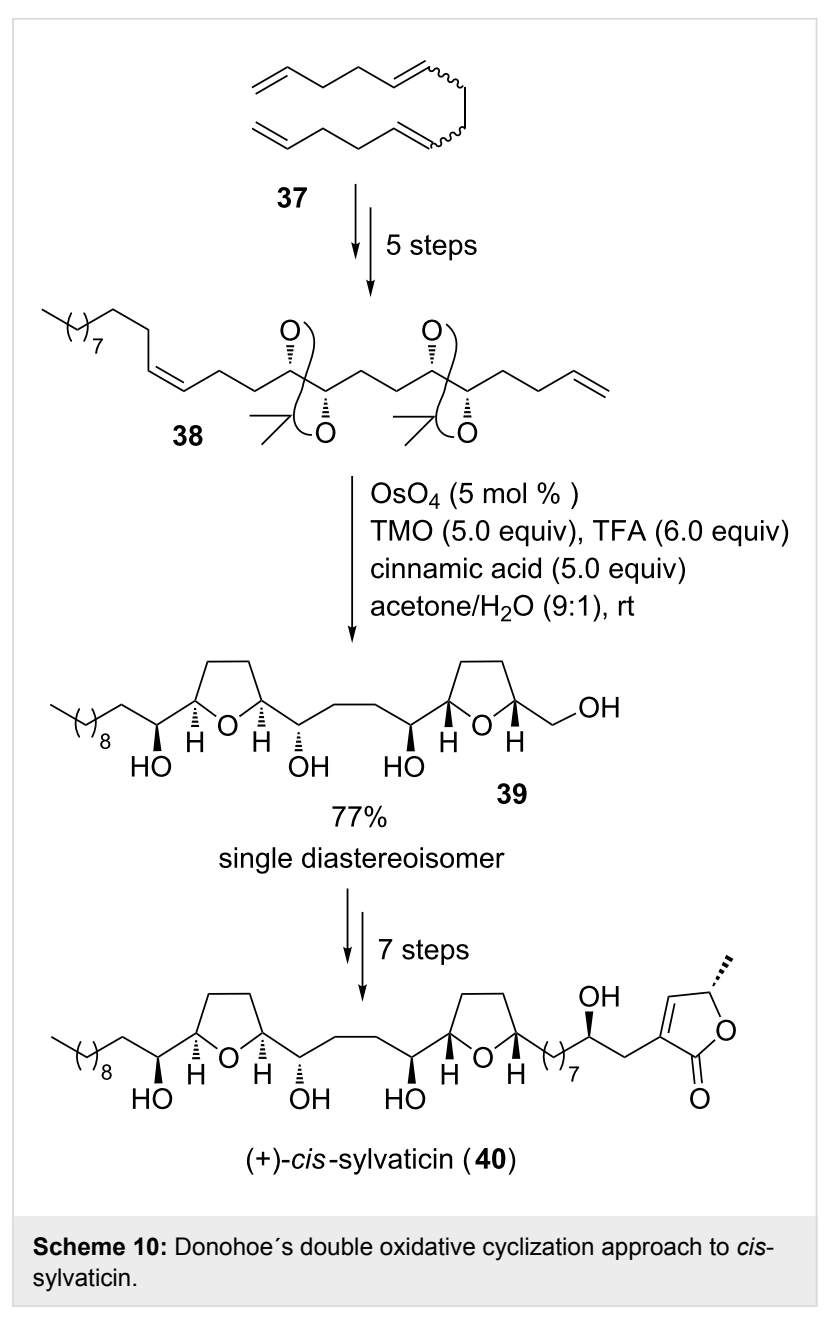

Another total synthesis of $c i s$-sylvaticin (40) has been published by Brown and co-workers in 2008 [92,97]. In this case, two permanganate-promoted type A oxidative cyclization reactions were used to establish the two THF rings of this acetogenin (Scheme 11). Both THF diols $\mathbf{4 3}$ and $\mathbf{4 7}$ were isolated as pure diastereoisomers with high diastereocontrol (dr 9:1 for $\mathbf{4 3}$ and dr 8.7:1 for 47, respectively) and then successfully connected in a silicon-tethered ring closing metathesis (RCM) [98] to provide the main backbone of cis-sylvaticin (40). Moreover, in 2009, Brown and co-workers reported on a short synthesis of the nonadjacent bis-THF core of cis-sylvaticin (40) making use of a permanganate-mediated bidirectional oxidative cyclization approach [99].

\section{Membranacin and membrarollin}

Membranacin (55) and membrarollin (62) are typical adjacent bis-THF acetogenins having a threo-cis-threo-cis-erythro configured core (Scheme 12 and Scheme 13). They were isolated from the seeds of the fruit tree Rollinia membranaceae by the Cortes group [100,101]. Previous studies demonstrated, that particularly adjacent bis-THF acetogenins exhibit highly potent 

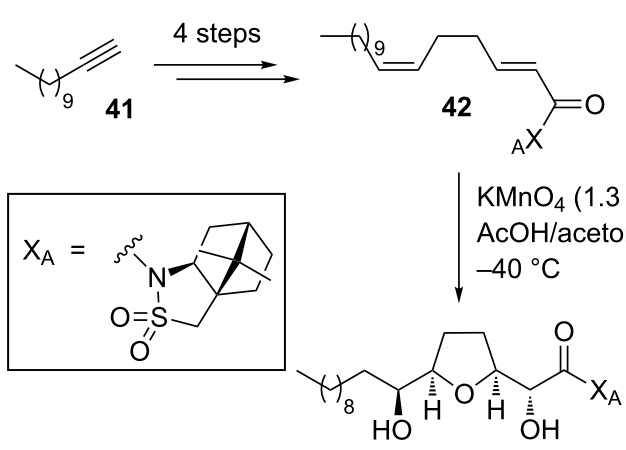

$67 \%$

43

+ diastereoisomer $9: 1 \mathrm{dr}$

$\downarrow 5$ steps

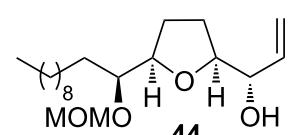<smiles>[R5][OH+][C@@H](COCc1ccccc1)NC/C=C\CC/C=C/C([X])=O</smiles>

$\mathrm{KMnO}_{4}$ (1.3 equiv),

AcOH/acetone (1:3)

$-40^{\circ} \mathrm{C}$

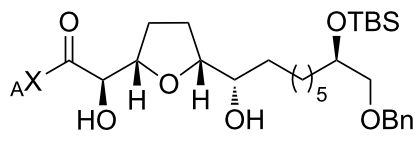

$61 \%$ 47

+ diastereoisomer 8.7:1 dr

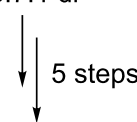

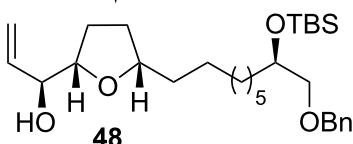
7 steps

(+)-cis-sylvaticin (40)

Scheme 11: Permanganate-mediated approach to cis-sylvaticin by Brown and co-workers.

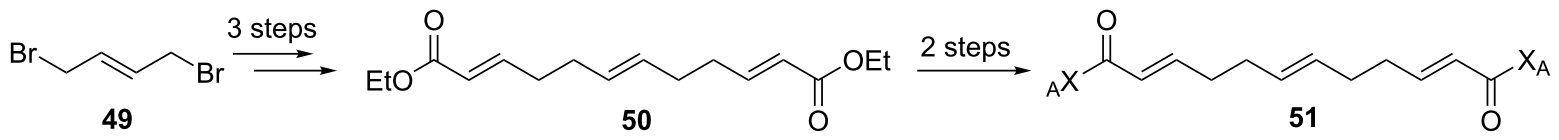

i) $\mathrm{KMnO}_{4}$ (2.6 equiv) Adogen 464 (5 mol \%) acetone/AcOH (3:2) ii) $\mathrm{NaIO}_{4}-\mathrm{SiO}_{2}, \mathrm{CH}_{2} \mathrm{Cl}_{2}$

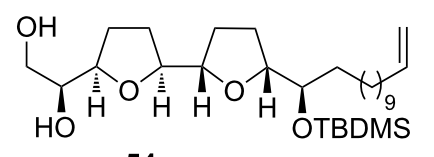

54

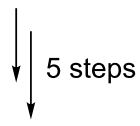<smiles>C1CCCCC1</smiles>

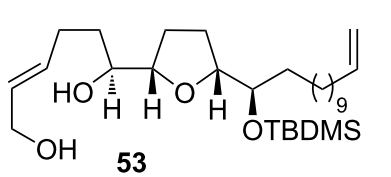

53

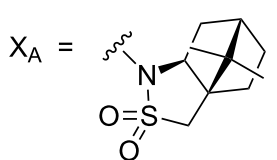

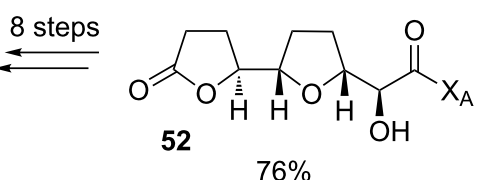

single diastereoisomer

Scheme 12: Total synthesis of membranacin using a $\mathrm{KMnO}_{4}$-mediated oxidative cyclization 


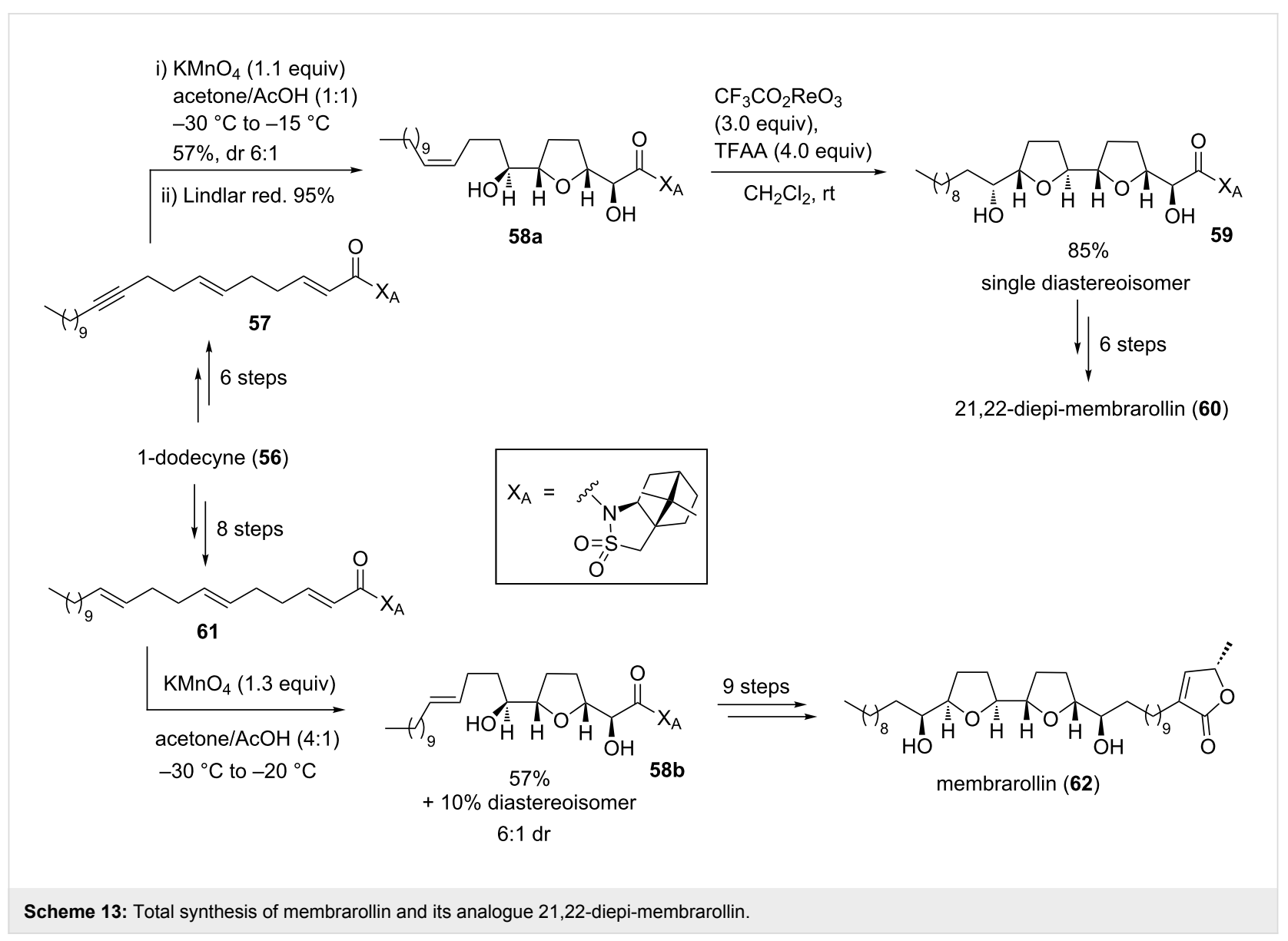

tumor growth inhibitory activity. Detailed investigations into the mode of action revealed that acetogenins inhibit cancer cell growth through the blockage of the mitochondrial NADHubiquinone oxidoreductase of complex I of the respiratory chain. In fact, membranacin (55) and membrarollin (62) are amongst the most potent complex I inhibitors identified to date [101]. As part of their studies towards the synthesis of adjacent bis-THF acetogenins including membranacin (55) and membrarollin (62), Brown and co-workers considered a twostage cyclization approach to control the stereochemistry within the THF backbone ring system.

The total synthesis of membranacin (55), developed in 2004 by Brown and co-workers, comprised metal-oxo and metal-peroxymediated oxidative cyclizations as the key steps [102] (Scheme 12). Thus, permanganate oxidation of triene 51, which can be synthesized in a few steps from $(E)$-1,4-dibromobut-2ene (49), followed by treatment of the crude reaction mixture with $\mathrm{NaIO}_{4}-\mathrm{SiO}_{2}$ proceeded efficiently to afford the single isolated diastereoisomeric lactone $\mathbf{5 2}$ in $76 \%$ yield. This lactone (52) was converted to enediol $\mathbf{5 3}$ in a further few steps. The second THF ring was then established using an epoxidation-cyclization sequence. Thus, asymmetric Sharpless epoxidation
(SAE) $[103,104]$ yielded an intermediary oxirane (not shown in Scheme 12) which was intramolecularly trapped by attack of the remote hydroxy group to afford bis-THF 54, a key intermediate en route to membranacin (55) (Scheme 12) [102].

One year later, in 2005, Brown and co-workers achieved a total synthesis of 21,22-diepi-membrarollin (60) [105], possessing an adjacent bis-THF motif present in various acetogenins (e.g. carolin A [106]), by applying sequential metal-oxo mediated oxidative cyclizations to introduce six of the seven stereogenic centers (Scheme 13). The required dienyne 57 was prepared from commercially available 1-dodecyne (56). Permanganatepromoted oxidation of dienyne $\mathbf{5 7}$ proceeded rapidly and selectively at low temperatures, affording the corresponding diastereomeric THF diols as a separable mixture (dr 6:1, major stereoisomer shown in Scheme 13). Semi hydrogenation of the triple bond using the Lindlar catalyst gave the bis-homoallylic alcohol 58a, which underwent an efficient acyl perrhenatemediated hydroxy-directed oxidative cyclization to afford a single isolated bis-THF 59 in excellent yield. A few subsequent steps were required to finish the synthesis of 21,22-diepimembrarollin (60), notably avoiding the requirement for any hydroxy protecting groups. 
The first total synthesis of membrarollin (62, Scheme 13) was finally disclosed by Brown and co-workers in 2009 [107]. Similarly starting from 1-dodecyne (56), triene system 61 was selectively oxidized using a permanganate-mediated oxidative cyclization affording two separable diastereoisomeric THF diols in $67 \%$ yield (only major isomer $\mathbf{5 8 b}$ shown in Scheme 13 ). It is worth noting that this oxidative cyclization proceeded with high chemoselectivity leaving the remote $\mathrm{C}-\mathrm{C}$-double bond unreacted. For the formation of the adjacent THF ring different and stereodivergent strategies were studied [107]. The relative and absolute stereochemistry required to prepare natural membrarollin (62) was obtained using a perrhenate-mediated type B' cyclization of THF diol $\mathbf{5 8 b}$ (not shown in Scheme 13).

\section{Rollidecin C and D}

Rollidecin C (69) and D (70) belong to the class of adjacent bisTHF acetogenins. In contrast to other representatives of this subgroup of acetogenins they are lacking one of the secondary alcohols usually framing the bis-THF core (Scheme 14). They were isolated from the leaves of Rollinia mucosa [108] and shown to exhibit cytotoxicity against six human tumor cell lines. Rollidecin C (69) was found to be more potent than rollidecin D (70) with selectivity toward the colon cell line HT-29 [108]. In 2001, the groups of Sinha and Keinan reported on a stereoselective synthesis of rollidecin C (69) and D (70) [109] using the tandem oxidative polycyclization reaction with trifluoro-acetylperrhenate, a synthetic method first reported in 1995 [110,111]. Bis-homoallylic dienols 65 and 66 were synthesized from trans-ethyl heptadec-4-enoate (63) via diene $\mathbf{6 4}$ A Re(VII)-mediated type $\mathrm{C}$ oxidative cyclization furnished the bis-THF products 67 and 68 in $49 \%$ and $29 \%$ yield, respectively. Both THF rings were introduced with excellent diastereoselectivity in a single step transformation at the final stages of the total syntheses of rollidecin C (69) and D (70) (Scheme 14).

Similar rhenium-mediated type $\mathrm{C}$ oxidative cyclizations were also successfully applied in total syntheses of further acetogenins by Sinha and Keinan, e.g., asimicin $[112,113]$, bullatacin [112-114], trilobacin [115] and even to the tris-THF acetogenins goniocin [116] and cyclogoniodenin T [116].

\section{Asimilobin and gigantetrocin $\mathrm{A}$}

Asimilobin (74) is a bis-THF acetogenin containing two 2,5trans-configured THFs [117]. It has originally been isolated from the seeds of Asimina triloba [118] but has also been found in extracts of the bark of Goniothalamus giganteus (Annonaceae) [119] by McLaughlin and co-workers [120,121]. In 1999, Wang and Shi et al. disclosed the first total synthesis of (-)-asimilobin (74) and its diastereomer using a highly efficient and stereocontrolled synthetic strategy to construct the desired bis-THF ring building block $\mathbf{7 3}$ in two steps (Scheme 15)

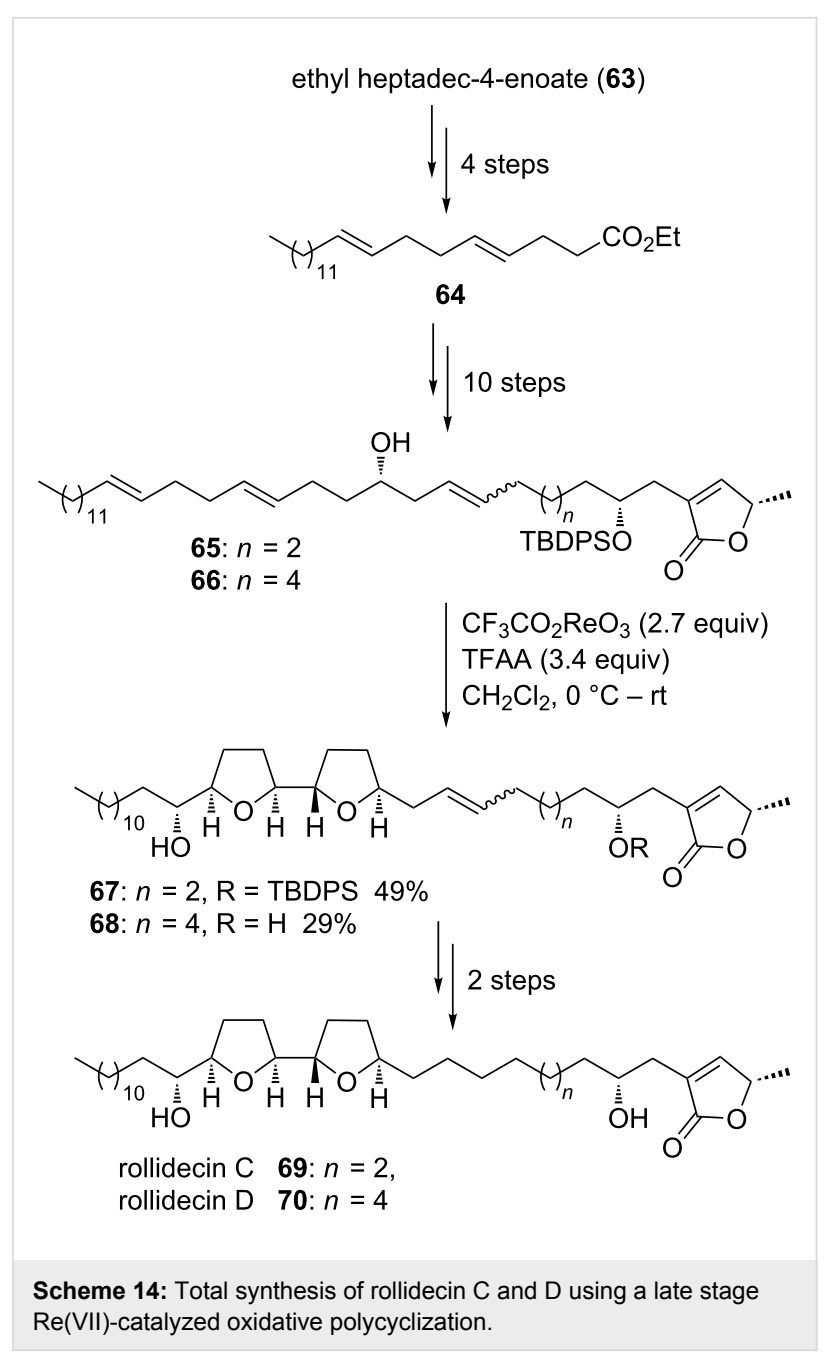

$[120,121]$. Thus, starting from commercially available trans1,5,9-decatriene (71) a stereo- and positionselective Sharpless $\mathrm{AD}$ reaction [86-88] provided $C_{2}$-symmetric diol $72(\mathrm{R}=\mathrm{H})$ in high selectivity (ee $>94 \%$ ). Subsequent $\mathrm{Co}$ (II)-mediated oxidative type B' cyclization of dienediol $72(\mathrm{R}=\mathrm{H})$ proceeded in good yield (78\%) and with high diastereoselectivity (de 96\%) to give $C_{2}$-symmetric bis-THF product 73 (Scheme 15). The natural product was then assembled in a further 10 steps (Scheme 15) [120,121].

Subsequently, Shi and co-workers successfully applied their synthetic strategy to the first total synthesis of gigantetrocin A (76) $[122,123]$, a mono-THF acetogenin, isolated from Goniothalamus giganteus by McLaughlin and co-workers [124]. This time, mono-protected dienediol $72(\mathrm{R}=\mathrm{MOM})$ was cyclized to form trans-THF compound $\mathbf{7 5}$ in $74 \%$ yield (de $>95 \%$ ) using $\mathrm{Co}(\operatorname{modp})_{2}$ as a catalyst under oxygen atmosphere (Scheme 15). Finally, the synthesis of gigantetrocin A (76) has been achieved in seventeen steps from chiral mono-protected dienediol $\mathbf{7 2}$ $(\mathrm{R}=\mathrm{MOM})[122,123]$. 


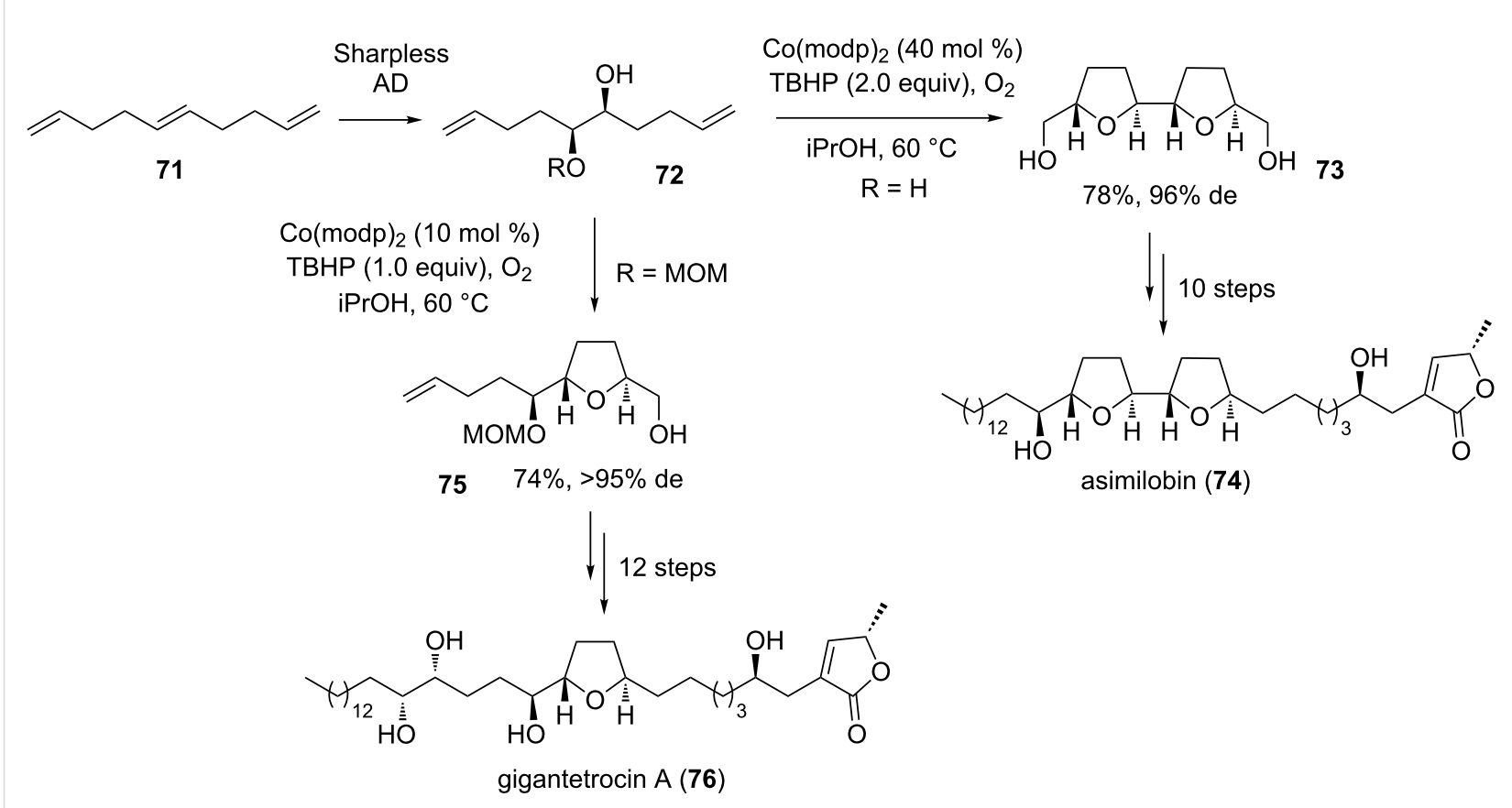

Scheme 15: Co(II)-catalyzed oxidative cyclization in the total synthesis of asimilobin and gigantetrocin A.

Further acetogenins which have been synthesized through Co(II)-mediated type B' oxidative cyclizations include mucocin, a known mono-THF representative, by Evans et al. [125] and the bis-THF acetogenin bullatacin by Pagenkopf and co-workers [126]. The latter group also employed this methodology in the total synthesis of aplysiallene [127], and more recently to bovidic acid [128] and cyclocapitelline [129].

\section{Oxidative cyclizations in the synthesis of terpenoid natural products Linalool oxide}

The monoterpenoid trans-(+)-linalool oxide (79), containing a 2,2,5-trisubstituted THF ring, can be found in food and beverages as well as essential oils and is used as powerful sweetwoody penetrating aroma component in the perfume and flavoring industry [130]. Several syntheses have been published between 1981 and 2010 using a range of different strategies (e.g. enzymatic procedures, Sn- and Pd-catalyzed methods or even anodic oxidations) [131-136]. In 2014 the Brown group proposed an auxiliary-controlled synthesis of trans-(+)-linalool oxide (79) using a permanganate-mediated type A oxidative cyclization as the key step (Scheme 16) [137]. Thus, 1,5-diene 77 was subjected to an oxidative cyclization using stoichiometric amounts of sodium permanganate to furnish trans-THF diol 78 in $73 \%$ yield with an excellent diastereomeric ratio of 97:3 induced by a cyclohexanol derived chiral auxiliary. This key intermediate was subsequently converted to natural trans(+)-linalool oxide (79) in a further few steps.

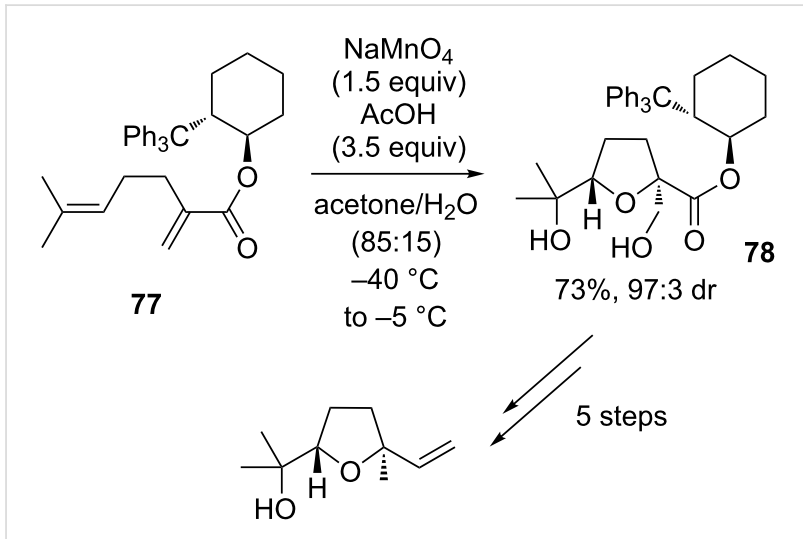

trans-(+)-linalool oxide (79)

Scheme 16: Mn(VII)-catalyzed oxidative cyclization of a 1,5-diene in the synthesis of trans-(+)-linalool oxide.

\section{Teurilene}

Teurilene (82) is a squalene-derived cytotoxic polyether which was originally extracted from the red algae Laurencia obtusa by Suzuki et al. [138,139]. Though it is $C_{\mathrm{S}^{-}}$-symmetric, it is structurally closely related to pentacyclic $C_{2}$-symmetric glabrescol [140], another triterpene natural product found in Jamaican endemic plant Spathelia glabrescens (Rutaceae) [141]. In 1999, Morimoto and co-workers reported on a stereoselective synthesis of the meso-tris-THF natural product teurilene (82) [142,143] (several previous total syntheses existed [144-151]) using an elegant two-directional approach (Scheme 17). 


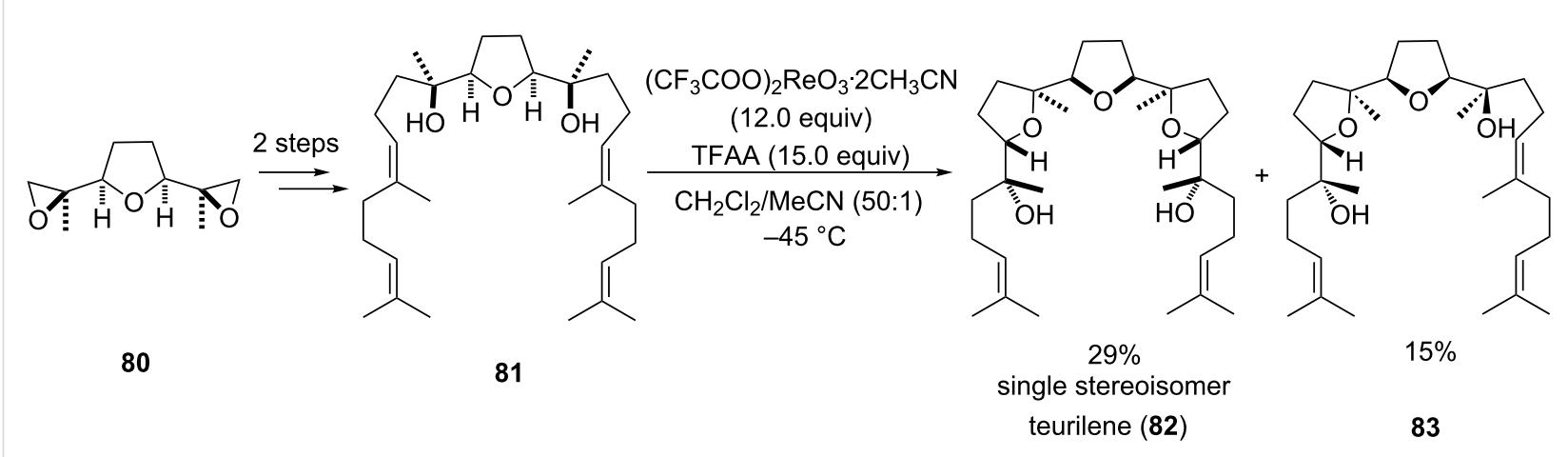

Scheme 17: $\operatorname{Re}(\mathrm{VII})$-catalyzed oxidative cyclization in the total synthesis of teurilene.

Thus, starting from a central THF diol $\mathbf{8 1}$ with a fully established carbon framework, which was derived from $C_{\mathrm{S}}$-symmetric bis-epoxide precursor $\mathbf{8 0}$, a double oxidative cyclization using $\operatorname{Re}(\mathrm{VII})$-catalysis furnished the natural product in $29 \%$ yield (Scheme 17). This (supposedly) type B' ring forming reaction occurred with high stereoselectivity for the transisomer and in addition a minor amount of the mono-cyclization product $\mathbf{8 3}$ was obtained.

\section{Eurylene}

Eurylene (87) represents yet another oxasqualenoid triterpene, sharing some structural similarity with teurilene and glabrescol, but other than the latter two, eurylene (87) is neither $C_{\mathrm{S}^{-}}$nor $C_{2}$-symmetric (Scheme 18). It has been isolated from the wood of Eurycoma longifolia by Itokawa et al. in 1991 [152] and was shown to exhibit cytotoxic properties against lymphocytic leukemia. The first total synthesis by Ujihara et al. [153] followed five years after its original discovery.

In 2000, the Morimoto group developed a total synthesis using two type B' cyclization steps ( $\mathrm{Re}(\mathrm{VII})$ and $\mathrm{Cr}(\mathrm{VI})$ catalysis) to form the THF-heterocycles of the natural product (Scheme 18) [154]. The linear precursor 84 was cyclized diastereoselectively to the mono-THF intermediate $\mathbf{8 5}$ with an oxorhenium(VII) complex and was subsequently subjected to the second oxidative cyclization using stoichiometric amounts of pyridinium chlorochromate (PCC) to give the bis-THF compound $\mathbf{8 6}$, which was easily converted to enantiomerically pure $(+)$-eurylene (87) (Scheme 18).

The Brown group published an enantioselective synthesis of the cis- and trans-THF fragments of eurylene (87) in 2010 [155] using an auxiliary controlled Mn(VII)-promoted oxidative cyclization to form THFs 90 and 93 (Scheme 19). Both THFderivatives had previously been prepared in a different approach and used as intermediates in a total synthesis of eurylene (87) by Kodama and co-workers [156]. Brown's perman-

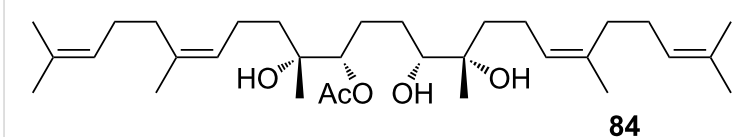

84

$\left(\mathrm{CF}_{3} \mathrm{CO}_{2}\right) \mathrm{ReO}_{3} \cdot 2 \mathrm{CH}_{3} \mathrm{CN}$ (8.0 equiv) TFAA (10.0 equiv) $\mathrm{CH}_{2} \mathrm{Cl}_{2} / \mathrm{CH}_{3} \mathrm{CN}(9: 1),-40{ }^{\circ} \mathrm{C}$

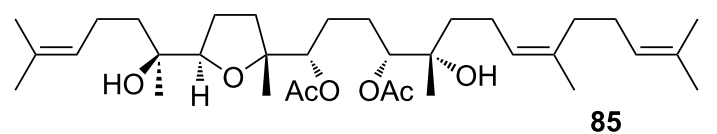

$84 \%$, single stereoisomer

85
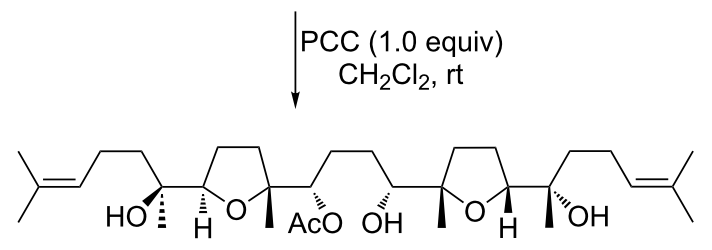

$47 \%$, single stereoisomer

86

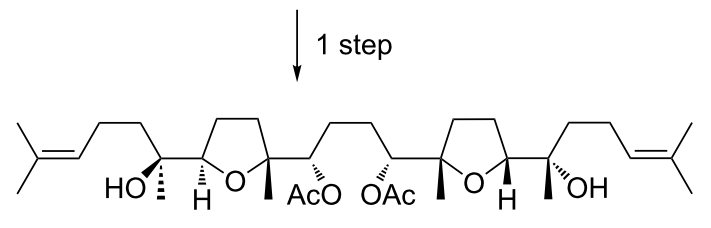

(+)-eurylene (87)

Scheme 18: Total synthesis of (+)-eurylene via Re(VII)- and $\mathrm{Cr}(\mathrm{VI})-$ mediated oxidative cyclizations.

ganate mediated oxidative cyclization of precursor $\mathbf{8 8}$ gave a yield of $78 \%$ and a diastereomeric ratio of $6.7: 1$ in favor for the desired product 89a. Though this reaction is cis-selective, cunningly, deoxygenation ultimately leads to the trans-THF fragment 90. The other THF subunit 93 of the natural product $\mathbf{8 7}$ was prepared via an oxidative mono-cyclization of triene $\mathbf{9 1 .}$ Thus, the desired cis-product 92a was obtained in 51\% yield together with $8 \%$ of its diastereoisomer $\mathbf{9 2 b}$ and a minor amount of the double cyclized product 92c. Both synthesized 


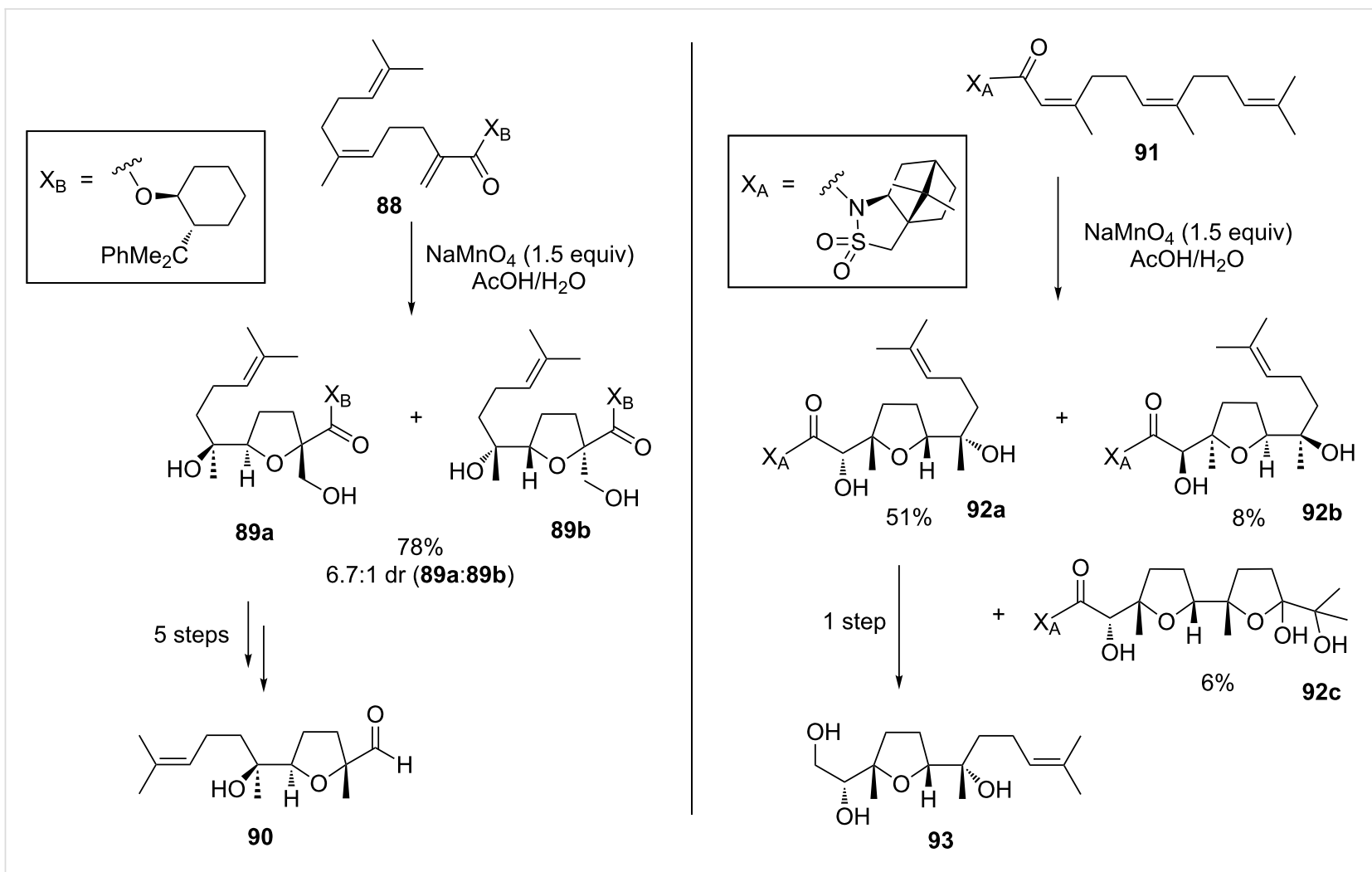

Scheme 19: Synthesis of cis- and trans-THF Rings of eurylene via Mn(VII)-mediated oxidative cyclizations.

THF fragments were consistent with those reported by Kodama [156] (Scheme 19).

\section{Venustatriol}

The tetracyclic oxasqualenoid venustatriol (96) was isolated in 1986 by Sakemi et al. from the red algae Laurentia venustra and exhibited antiviral activity against vesicular stomatitis virus (VSV) and herpes simplex virus type 1 (HSV-1) [157]. Hashimoto et al. reported a total synthesis of the natural product in $1988[158,159]$ employing a vanadium-catalyzed epoxidation as a key step in the stereoselective formation of the THF ring, whilst the Corey group achieved a total synthesis using a PCC-mediated oxidative type B cyclization in the same year (Scheme 20) [160].

Diol 94, derived from geraniol, was diastereoselectively converted into the THF derivative 95 in a yield of $43 \%$ using an oxochromium(VI) complex. Venustatriol (96) could then be obtained by $\mathrm{C}-\mathrm{C}$-coupling with the corresponding THP fragment in an enantioselective fashion.

\section{Glaciapyrrol A}

Glaciapyrrol A (100), B and C form a family of pyrrolo sesquiterpenoids which have been isolated in 2005 from a marine Streptomyces sp. (NPS008187) by Macherla et al. [161].

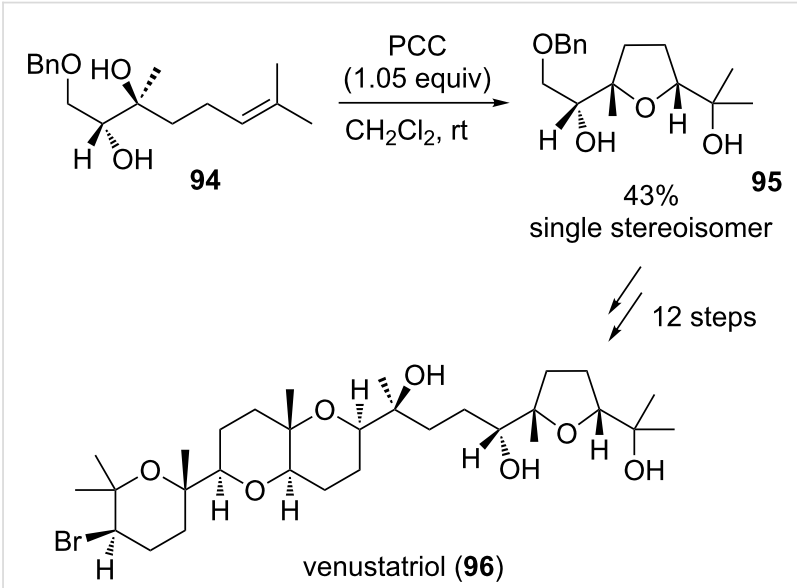

Scheme 20: $\mathrm{Cr}(\mathrm{VI})$-catalyzed oxidative cyclization in the total synthesis of venustatriol by Corey et al.

The only established total synthesis has been developed by the Dickschat group in 2011 [162] using a type A Ru(VIII)-catalyzed oxidative cyclization as the key step (Scheme 21).

Both neryl benzoate (97) as well as geranyl benzoate (98) have been converted into the corresponding THF diols 99 using an established oxidative cyclization protocol $[15,163,164]$. The diastereoselectivity of the reaction varied depending on the sol- 


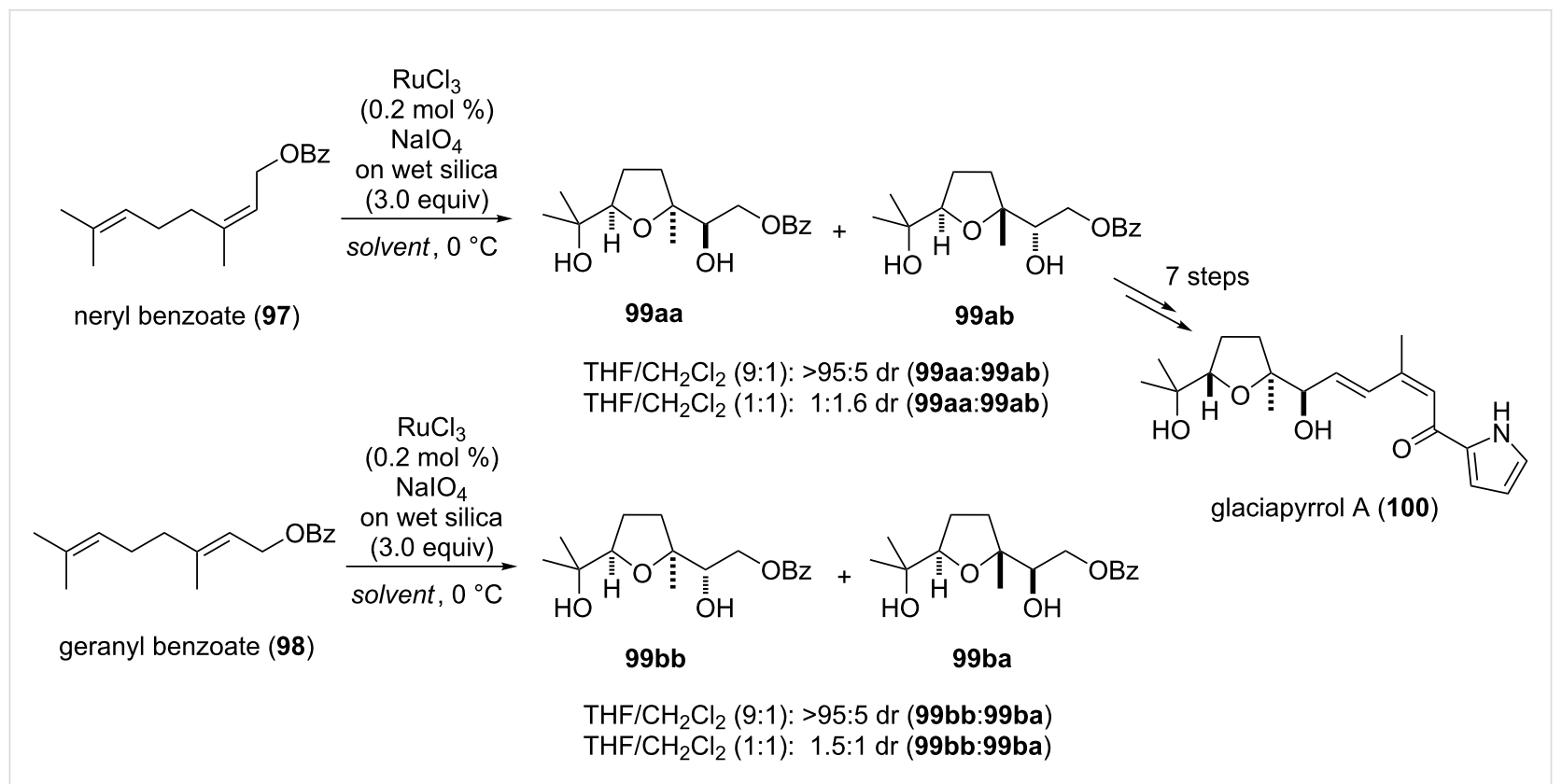

Scheme 21: Ru(VIII)-catalyzed oxidative cyclization of a 1,5-diene in the synthesis and evaluation of its stereochemistry of glaciapyrrol A.

vent composition used [15]. Therefore, reaction of 97 using $\mathrm{THF} /$ dichloromethane (9:1) as the solvent mixture resulted in a selective formation of cis-THF 99aa, whereas a 1:1 mixture of the same solvents gave a diastereomeric ratio of $1: 1.6$ in favor for the trans-isomer 99ab. Oxidative cyclization of transconfigured starting material $\mathbf{9 8}$ proceeded with similar efficiency. In this case a 9:1 solvent ratio gave 99bb selectively and a 1:1 solvent mixture resulted in a diastereomeric ratio of 1.5:1, favoring 99bb (Scheme 21). Glaciapyrrol A (100) was finally obtained from 99ab by deprotection of the benzoyl group and an olefination to connect the pyrrole subunit of the natural product.

\section{Leucosceptroids A-D}

Leucosceptroids A (105a) and B (105b) have been isolated in 2010 by Luo et al. from the Chinese shrub Leucosceptrum canum [165]. One year later the same group was able to isolate two additional leucosceptroids C (105c) and D (105d) from the leaves of the same plant [166]. This family of sesterterpenoids is believed to be beneficial to the plant as part of a defense mechanism against herbivores. The first total synthesis of leucosceptroid B (105b) was established in 2013 by Huang et al. [167] and two other total syntheses of leucosceptroids A (105a) and B (105b) followed two years later [168,169]. The common tricyclic core structure of the natural products had already been synthesized in 2011 by the Horne group [170], using a TPAP-catalyzed type B oxidative cyclization to form the densely substituted THF diol motif following a protocol of our group [25] (Scheme 22).
The 5,6-dihydroxyalkene 101 was obtained from D-mannitol diacetonide via oxidation and C-C-bond formation. The oxidative cyclization catalyzed by Ru(VII) yielded THF diol 102 in $55 \%$ yield as a single diastereoisomer, without considering the configuration of the protected alcohol, as this position was subsequently oxidized to enable a Sonogashira cross-coupling to access 103. The tricyclic core structure 104 could be obtained via an intramolecular Diels-Alder reaction, epoxidation and protection (Scheme 22) [170].

\section{Conclusion}

The direct oxidative cyclization of 1,5-dienes is known for more than 90 years, since the early finding by Kötz and Steche in 1924. While mechanistic and stereochemical aspects were in the center of research for many years, during the last two or three decades this unusual reaction has been advanced to a powerful and reliable strategy to establish 2,5-disubstituted cis-THF diols from very simple (often achiral) diene substrates. The reaction proceeds with a substantial increase in structural and stereochemical complexity from the starting material to the product. A similar development can be stated for the mechanistically closely related oxidative cyclizations of 5,6-dihydroxyalkenes and 5-hydroxyalkenes. All these processes are stereochemically predictable and the double bond geometry dictates the relative vicinal hydroxy ether stereochemistry at both sides adjacent to the THF-oxygen. 2,5-Disubstituted trans-THFs are still significantly harder to prepare using these strategies or require specific procedures. Similarly, the control of the absolute stereochemistry remains a challenge to be solved in future investigations. 


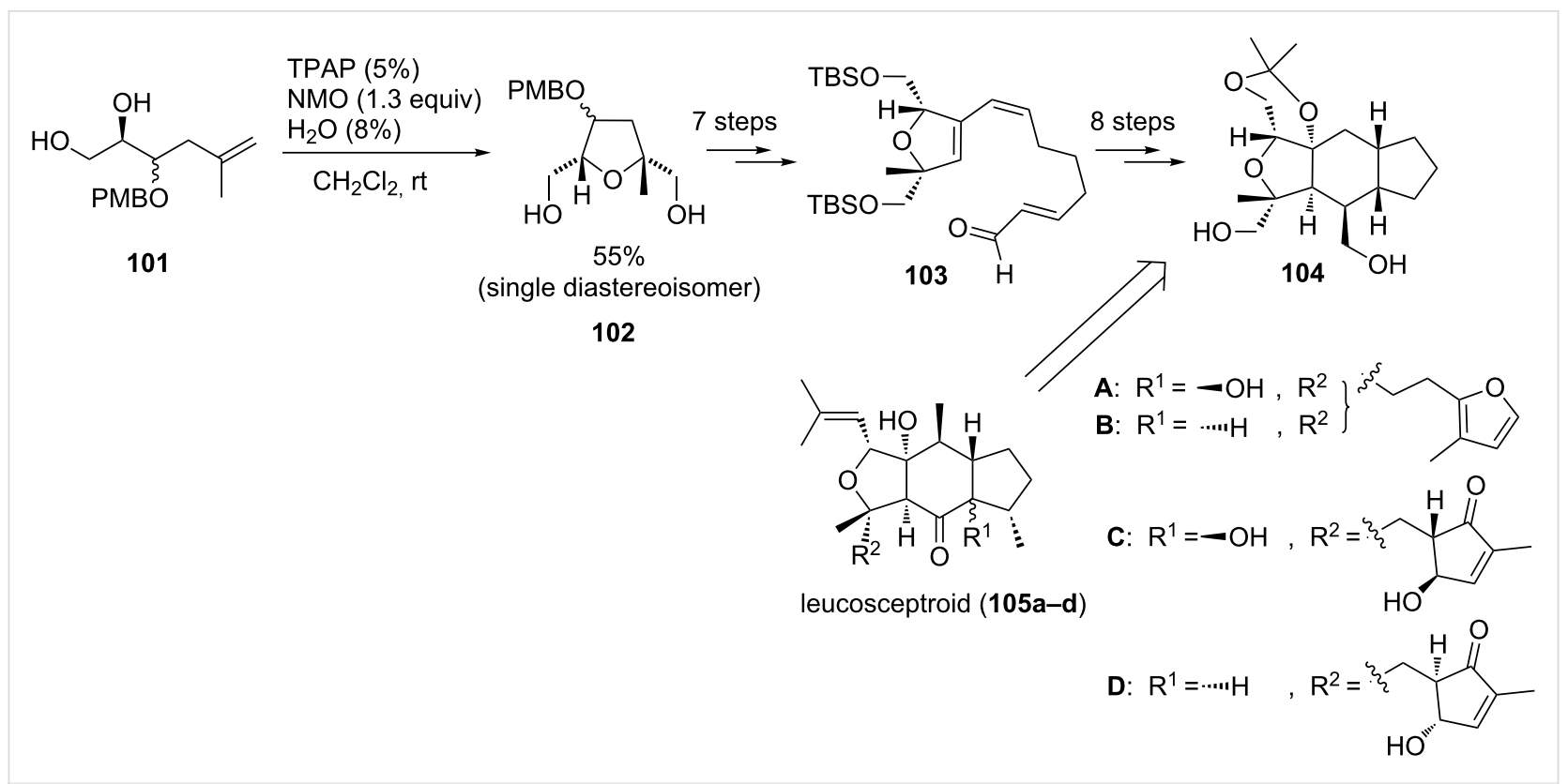

Scheme 22: Ru(VII)-catalyzed oxidative cyclization of a 5,6-dihydroxy alkene in the synthesis of the core structure of the leucosceptroids A-D.

To date there is only a single report on an enantioselective oxidative cyclization of a 1,5-diene using permanganate together with a chiral counter ion. Other strategies use either a chiral auxiliary, a subsequent desymmetrization or start from a chiral 5,6-dihydroxy alkene or 5-hydroxy alkene substrate and proceed in a diastereoselective fashion to yield optically pure products. Though the latter procedures are quite powerful, the development of a catalytic asymmetric oxidative diene cyclization appears still a worthwhile task to be solved. Moreover, one can expect that future applications in target-oriented and natural product synthesis will also apply the same reaction methodology for the construction of THP or even oxepan compounds.

Overlooking these future directions, the direct oxidative cyclization of 1,5-dienes and mechanistically related oxidative THF forming reactions seem now to be firmly established methods for the application in complex total synthesis and are expected to deliver further exciting examples. More than 25 successful examples from the past three decades from different classes of natural products (including carbohydrates, polyketides, amino acids, fatty acids as well as acetogenins and terpenoids) are summarized in this review article.

\section{Acknowledgements}

Our research in this area is generously funded by the Deutsche Forschungsgemeinschaft (DFG) and the Fonds der Chemischen Industrie (FCI). In addition, individual fellowships by the ErnstSchering-Stiftung, the Dierks-von-Zweck-Stiftung and the Deutsche Bundesstiftung Umwelt (DBU) are gratefully acknowledged.

\section{References}

1. Walba, D. M.; Edwards, P. D. Tetrahedron Lett. 1980, 21, 3531-3534. doi:10.1016/0040-4039(80)80226-7

2. Kocieński, P. J.; Brown, R. C. D.; Pommier, A.; Procter, M.; Schmidt, B. J. Chem. Soc., Perkin Trans. 1 1998, 9-40. doi:10.1039/a705385a

3. Hartung, J.; Greb, M. J. Organomet. Chem. 2002, 661, 67-84. doi:10.1016/S0022-328X(02)01807-7

4. Piccialli, V. Synthesis 2007, 2585-2607. doi:10.1055/s-2007-983835

5. Pilgrim, B. S.; Donohoe, T. J. J. Org. Chem. 2013, 78, 2149-2167. doi:10.1021/jo302719y

6. Sheikh, N. S. Org. Biomol. Chem. 2014, 12, 9492-9504. doi:10.1039/C4OB01491J

7. Kötz, A.; Steche, T. J. Prakt. Chem. 1924, 107, 193-210. doi:10.1002/prac.19241070509

8. Klein, E.; Rojahn, W. Tetrahedron 1965, 21, 2353-2358. doi:10.1016/S0040-4020(01)93889-X

9. Baldwin, J. E.; Crossley, M. J.; Lehtonen, E.-M. M. J. Chem. Soc., Chem. Commun. 1979, 918-920. doi:10.1039/c39790000918

10. Walba, D. M.; Wand, M. D.; Wilkes, M. C. J. Am. Chem. Soc. 1979, 101, 4396-4397. doi:10.1021/ja00509a069

11. Wolfe, S.; Ingold, C. F. J. Am. Chem. Soc. 1981, 103, 940-941. doi:10.1021/ja00394a038

12. Poething, A.; Strassner, T. Collect. Czech. Chem. Commun. 2007, 72, 715-727. doi:10.1135/cccc20070715

13. Poething, A.; Strassner, T. J. Org. Chem. 2010, 75, 1967-1973. doi:10.1021/jo100147e

14. di Dio, P. J.; Zahn, S.; Stark, C. B. W.; Kirchner, B. Z. Naturforsch. 2010, 65b, 367-375. doi:10.1515/znb-2010-0321

15. Roth, S.; Göhler, S.; Cheng, H.; Stark, C. B. W. Eur. J. Org. Chem. 2005, 4109-4118. doi:10.1002/ejoc.200500052

16. Jalce, G.; Franck, X.; Figadère, B. Tetrahedron: Asymmetry 2009, 20, 25372581. doi:10.1016/j.tetasy.2009.10.034 
17. Piccialli, V. Molecules 2014, 19, 6534-6582. doi:10.3390/molecules 19056534

18. Plietker, B. Synthesis 2005, 15, 2453-2472. doi:10.1055/s-2005-872172

19. Murahashi, S.-I.; Komiya, N. In Ruthenium Catalyzed Oxidation for Organic Synthesis in Modern Oxidation Methods; Bäckvall, J.-E., Ed.; Wiley-VCH: Weinheim, Germany, 2010; pp 241-245.

20. Roth, S.; Stark, C. B. W. Angew. Chem., Int. Ed. 2006, 45, 6218-6221. doi:10.1002/anie.200504572

21. Cecil, A. R. L.; Brown, R. C. D. Tetrahedron Lett. 2004, 45, 7269-7271. doi:10.1016/j.tetlet.2004.08.023

22. Piccialli, V. Tetrahedron Lett. 2000, 41, 3731-3733. doi:10.1016/S0040-4039(00)00476-7

23. Piccialli, V.; Borbone, N.; Oliviero, G. Tetrahedron Lett. 2007, 48, 5131-5135. doi:10.1016/j.tetlet.2007.05.078

24. Donohoe, T. J.; Butterworth, S. Angew. Chem., Int. Ed. 2003, 42, 948-951. doi:10.1002/anie.200390253

25. Cheng, H.; Stark, C. B. W. Angew. Chem., Int. Ed. 2010, 49, 1587-1590. doi:10.1002/anie.200903090

26. Walba, D. M.; Stoudt, G. S. Tetrahedron Lett. 1982, 23, 727-730. doi:10.1016/S0040-4039(00)86932-4

27. Shen, Z.; Sinha, S. C. Tetrahedron 2008, 64, 1603-1611. doi:10.1016/j.tet.2007.11.089

28. Wang, Z.-M.; Tian, S.-K.; Shi, M. Tetrahedron: Asymmetry 1999, 10, 667-670. doi:10.1016/S0957-4166(99)00039-7

29. Menéndez Pérez, B.; Schuch, D.; Hartung, J. Org. Biomol. Chem. 2008, 6, 3532-3541. doi:10.1039/B804588G

30. Tanaka, T.; Hatano, K.; Watanabe, M.; Abbas, H. K. J. Nat. Toxins 1996, 5, 317-329.

31. Donohoe, T. J.; Butterworth, S. Angew. Chem., Int. Ed. 2003, 42, 948-951. doi:10.1002/anie.200390253

32. Koerner, T. A. W., Jr.; Voll, R. J.; Younathan, E. S. Carbohydr. Res. 1977, 59, 403-416. doi:10.1016/S0008-6215(00)83181-X

33. Bennek, J. A.; Gray, G. R. J. Org. Chem. 1987, 52, 892-897. doi:10.1021/jo00381a030

34. van Delft, F. L.; van der Marel, G. A.; van Boom, H. J. Tetrahedron Lett. 1994, 35, 1091-1094. doi:10.1016/S0040-4039(00)79973-4

35. van Delft, F. L.; Rob, A.; Valentijn, P. M.; van der Marel, G. A.; van Boom, J. H. J. Carbohydr. Chem. 1999, 18, 165-190. doi:10.1080/07328309908543989

36. Persky, R.; Albeck, A. J. Org. Chem. 2000, 65, 5632-5638. doi:10.1021/jo0003908

37. Das, B.; Kumar, D. N. Tetrahedron Lett. 2010, 51, 6011-6013. doi:10.1016/j.tetlet.2010.09.049

38. Aragão-Leoneti, V.; Carvalho, I. Tetrahedron Lett. 2013, 54, 1087-1089. doi:10.1016/j.tetlet.2012.12.062

39. Yuan, C.; Hollingsworth, I. R. Lett. Org. Chem. 2013, 10, 77-84. doi:10.2174/1570178611310020002

40. Kiss, J.; Furter, H.; Lohse, F.; Hardegger, E. Helv. Chim. Acta 1961, 44, 141-147. doi:10.1002/hlca.19610440119

41. Hardegger, E.; Furter, H.; Kiss, J. Helv. Chim. Acta 1958, 41, 2401-2410. doi:10.1002/hlca.19580410750

42. Sakai, R.; Koike, T.; Sasaki, M.; Shimamoto, K.; Oiwa, C.; Yano, A.; Suzuki, K.; Tachibana, K.; Kamiya, H. Org. Lett. 2001, 3, 1479-1482. doi:10.1021/ol015798I

43. Lee, H.-Y.; Lee, S.-S.; Kim, H. S.; Lee, K. M. Eur. J. Org. Chem. 2012, 4192-4199. doi:10.1002/ejoc.201200439
44. Sasaki, M.; Tsubone, K.; Aoki, K.; Akiyama, N.; Shoji, M.; Oikawa, M.; Sakai, R.; Shimamoto, K. J. Org. Chem. 2008, 73, 264-273. doi:10.1021/jo702116c

45. Shoji, M.; Akiyama, N.; Tsubone, K.; Lash, L. L.; Sanders, J. M.; Swanson, G. T.; Sakai, R.; Shimamoto, K.; Oikawa, M.; Sasaki, M. J. Org. Chem. 2006, 71, 5208-5220. doi:10.1021/jo0605593

46. Sasaki, M.; Tsubone, K.; Shoji, M.; Oikawa, M.; Shimamoto, K.; Sakai, R. Bioorg. Med. Chem. Lett. 2006, 16, 5784-5787. doi:10.1016/j.bmcl.2006.08.082

47. Takahashi, K.; Matsumura, T.; Corbin, G. R. M.; Ishihara, J.; Hatakeyama, S. J. Org. Chem. 2006, 71, 4227-4231. doi:10.1021/jo060410r

48. Lygo, B.; Slack, D.; Wilson, C. Tetrahedron Lett. 2005, 46, 6629-6632. doi:10.1016/j.tetlet.2005.07.159

49. Albarella, L.; Musumeci, D.; Sica, D. Eur. J. Org. Chem. 2001, 997-1003. doi:10.1002/1099-0690(200103)2001:5<997::AID-EJOC997>3.0.CO;2 $-7$

50. Ratcliffe, R.; Rodehorst, R. J. Org. Chem. 1970, 35, 4000-4002. doi:10.1021/jo00836a108

51. Schmidt, A.-K. C.; Stark, C. B. W. Org. Lett. 2011, 13, 4164-4167. doi:10.1021/ol2014335

52. Donohoe, T. J.; Winship, P. C. M.; Tatton, M. R.; Szeto, P. Angew. Chem., Int. Ed. 2011, 50, 7604-7606. doi:10.1002/anie.201102525

53. Jana, R.; Pathak, T. P.; Sigman, M. S. Chem. Rev. 2011, 111, 1417-1492. doi:10.1021/cr100327p

54. Heravi, M. M.; Hashemi, E.; Nazari, N. Mol. Diversity 2014, 18, 441-472. doi:10.1007/s11030-014-9510-1

55. Liu, C.; Hermann, T. E. J. Biol. Chem. 1978, 253, 5892-5894.

56. Liu, W.-C.; Slusarchyk, D. S.; Astle, G.; Trejo, W. H.; Brown, W. E.; Meyers, E. J. Antibiot. 1978, 31, 815-819. doi:10.7164/antibiotics.31.815

57. Toeplitz, B. K.; Cohen, A. I.; Funke, P. T.; Parker, W. L.; Gougoutas, J. Z. J. Am. Chem. Soc. 1979, 101, 3344-3353. doi:10.1021/ja00506a035

58. Putney, J. W., Ed. Calcium Signaling; CRC/Taylor \& Francis: Boca Raton, Florida, 2006.

59. Li, Y.; Cooksey, J. P.; Gao, Z.; Kocieński, P. J.; McAteer, S. M.; Snaddon, T. N. Synthesis 2011, 104-108. doi:10.1055/s-0030-1258327

60. Gao, Z.; Li, Y.; Cooksey, J. P.; Snaddon, T. N.; Schunk, S.; Viseux, E. M. E.; McAteer, S. M.; Kocienski, P. J. Angew. Chem., Int. Ed. 2009, 48, 5022-5025. doi:10.1002/anie.200901608

61. Evans, D. A.; Dow, R. L.; Shih, T. L.; Takacs, J. M.; Zahler, R. J. Am. Chem. Soc. 1990, 112, 5290-5313. doi:10.1021/ja00169a042

62. Hanessian, S.; Cooke, N. G.; DeHoff, B.; Sakito, Y. J. Am. Chem. Soc. 1990, 112, 5276-5290. doi:10.1021/ja00169a041

63. Spino, C.; Weiler, L. Tetrahedron Lett. 1987, 28, 731-734. doi:10.1016/S0040-4039(01)80974-6

64. Walba, D. M.; Edwards, P. D. Tetrahedron Lett. 1980, 21, 3531-3534. doi:10.1016/0040-4039(80)80226-7

65. Kobayashi, J.; Tsuda, M.; Ishibashi, M.; Shigemori, H.; Yamasu, T.; Hirota, H.; Sasaki, T. J. Antibiot. 1991, 44, 1259-1261. doi:10.7164/antibiotics.44.1259

66. Kobayashi, J.; Kubota, T. J. Nat. Prod. 2007, 70, 451-460. doi:10.1021/np0605844

67. Mahapatra, S.; Carter, R. G. Angew. Chem., Int. Ed. 2012, 51, 7948-7951. doi:10.1002/anie.201203935 
68. Mahapatra, S.; Carter, R. G. J. Am. Chem. Soc. 2013, 135, 10792-10803. doi:10.1021/ja404796n

69. Valot, G.; Regens, C. S.; O'Malley, D. P.; Godineau, E.; Takikawa, H.; Fürstner, A. Angew. Chem., Int. Ed. 2013, 52, 9534-9538. doi:10.1002/anie.201301700

70. Valot, G.; Mailhol, D.; Regens, C. S.; O'Malley, D. P.; Godineau, E.; Takikawa, H.; Philipps, P.; Fürstner, A. Chem. - Eur. J. 2015, 21 , 2398-2408. doi:10.1002/chem.201405790

71. Palmer, C.; Morra, N. A.; Stevens, A. C.; Bajtos, B.; Machin, B. P.; Pagenkopf, B. L. Org. Lett. 2009, 11, 5614-5617. doi:10.1021/ol9023375

72. Gleye, C.; Duret, P.; Laurens, A.; Hocquemiller, R.; Cavé, A. J. Nat. Prod. 1998, 61, 576-579. doi:10.1021/np970494m

73. Hu, Y.; Cecil, A. R. L.; Frank, X.; Gleye, C.; Figadère, B.; Brown, R. C. D. Org. Biomol. Chem. 2006, 4, 1217-1219. doi:10.1039/b601943a

74. Adrian, J.; Stark, C. B. W. Org. Lett. 2014, 16, 5886-5889. doi:10.1021/ol502849y

75. Makabe, H.; Hattori, Y.; Tanaka, A.; Oritani, T. Org. Lett. 2002, 4 , 1083-1085. doi:10.1021/ol0102803

76. Cecil, A. R. L.; Brown, R. C. D. Org. Lett. 2002, 4, 3715-3718. doi:10.1021/ol026669n

77. Makabe, H.; Hattori, Y.; Kimura, Y.; Konno, H.; Abe, M.; Miyoshi, H.; Tanaka, A.; Oritani, T. Tetrahedron 2004, 60, 10651-10657. doi:10.1016/j.tet.2004.09.011

78. Cecil, A. R. L.; Hu, Y.; Vicent, M. J.; Duncan, R.; Brown, R. C. D. J. Org. Chem. 2004, 69, 3368-3374. doi:10.1021/jo049909g

79. Donohoe, T. J.; Butterworth, S. Angew. Chem., Int. Ed. 2005, 44, 4766-4768. doi:10.1002/anie.200500513

80. Göksel, H.; Stark, C. B. W. Org. Lett. 2006, 8, 3433-3436. doi:10.1021/ol060520k

81. Konno, H.; Okuno, Y.; Makabe, H.; Nosaka, K.; Onishi, A.; Abe, Y.; Sugimoto, A.; Akaji, K. Tetrahedron Lett. 2008, 49, 782-785. doi:10.1016/j.tetlet.2007.11.190

82. Makabe, H.; Kuwabara, A.; Hattori, Y.; Konno, H. Heterocycles 2009, 78, 2369-2376. doi:10.3987/COM-09-11741

83. Konno, H.; Makabe, H.; Hattori, Y.; Nosaka, K.; Akaji, K. Tetrahedron 2010, 66, 7946-7953. doi:10.1016/j.tet.2010.08.028

84. Brown, R. C. D.; Keily, J. F. Angew. Chem., Int. Ed. 2001, 40, 4496-4498. doi:10.1002/1521-3773(20011203)40:23<4496::AID-ANIE4496>3.0.C O;2-F

85. Abdel Ghani, S. B.; Chapman, J. M.; Figadère, B.; Herniman, J. M.; Langley, G. J., II; Niemann, S.; Brown, R. C. D. J. Org. Chem. 2009, 74, 6924-6928. doi:10.1021/jo9012578

86. Hentges, S. G.; Sharpless, K. B. J. Am. Chem. Soc. 1980, 102, 4263-4265. doi:10.1021/ja00532a050

87. Jacobsen, E. N.; Marko, I.; Mungall, W. S.; Schroeder, G.; Sharpless, K. B. J. Am. Chem. Soc. 1988, 110, 1968-1970. doi:10.1021/ja00214a053

88. Kolb, H. C.; Sharpless, K. B. Asymmetric dihydroxylation. In Transition Metals for Organic Synthesis; Beller, M.; Bolm, C., Eds.; Wiley-VCH: Weinheim, Germany, 2004; Vol. 2, pp 275-298. doi:10.1002/9783527619405.ch5e

89. Schmidt, A.-K. C.; Stark, C. B. W. Synthesis 2014, 46, 3283-3308. doi:10.1055/s-0033-1338650

90. Zhong, Y.-L.; Shing, T. K. M. J. Org. Chem. 1997, 62, 2622-2624. doi:10.1021/jo9621581

91. Palomo, J. M.; Cabrera, Z. Curr. Org. Synth. 2012, 9, 791-805. doi:10.2174/157017912803901628
92. Spurr, I. B.; Brown, R. C. B. Molecules 2010, 15, 460-501. doi:10.3390/molecules15010460

93. Mikolajczak, K. J.; Madrigal, R. V.; Rupprecht, J. K.; Hui, Y.-H.; Liu, Y.-M.; Smith, D. L.; McLaughlin, J. L. Experientia 1990, 46, 324-327. doi:10.1007/BF01951779

94. Shi, G.; Zeng, L.; Gu, Z.-m.; MacDougal, J. M.; McLaughlin, J. L. Heterocycles 1995, 41, 1785-1796. doi:10.3987/COM-95-7117

95. Donohoe, T. J.; Harris, R. M.; Burrows, J.; Parker, J. J. Am. Chem. Soc. 2006, 128, 13704-13705. doi:10.1021/ja0660148

96. Donohoe, T. J.; Harris, R. M.; Williams, O.; Hargaden, G. C.; Burrows, J.; Parker, J. J. Am. Chem. Soc. 2009, 131, 12854-12861. doi:10.1021/ja9049959

97. Brown, L. J.; Spurr, I. B.; Kemp, S. C.; Camp, N. P.; Gibson, K. R.; Brown, R. C. D. Org. Lett. 2008, 10, 2489-2492. doi:10.1021/ol800767e

98. Grubbs, R. H.; Miller, S. J.; Fu, G. C. Acc. Chem. Res. 1995, 28 , 446-452. doi:10.1021/ar00059a002

99. Bhunnoo, R. A.; Hobbs, H.; Laine, D. I.; Light, M. E.; Brown, R. C. D. Org. Biomol. Chem. 2009, 7, 1017-1024. doi:10.1039/b813201a

100.Saez, J.; Sahpaz, S.; Villaescusa, L.; Hocquemiller, R.; Cavé, A.; Cortes, D. J. Nat. Prod. 1993, 56, 351-356. doi:10.1021/np50093a007

101.González, M. C.; Lavaud, C.; Gallardo, T.; Zafra-Polo, M. C.; Cortes, D. Tetrahedron 1998, 54, 6079-6088. doi:10.1016/S0040-4020(98)00301-9

102. Head, G. D.; Whittingham, W. G.; Brown, R. C. D. Synlett 2004, 1437-1439. doi:10.1055/s-2004-825624

103. Katsuki, T.; Sharpless, K. B. J. Am. Chem. Soc. 1980, 102, 5974-5976. doi:10.1021/ja00538a077

104. Heravi, M. M.; Lashaki, T. B.; Poorahmad, N. Tetrahedron: Asymmetry 2015, 26, 405-495. doi:10.1016/j.tetasy.2015.03.006

105. Hu, Y.; Brown, R. C. D. Chem. Commun. 2005, 5636-5637. doi:10.1039/b512126d

106. Queiroz, E. F.; Roblot, F.; Figadère, B.; Laurens, A.; Duret, P.; Hocquemiller, R.; Cavé, A. J. Nat. Prod. 1998, 61, 34-39. doi:10.1021/np9703252

107.Morris, C. L.; Hu, Y.; Head, G. D.; Brown, L. J.; Whittingham, W. G.; Brown, R. C. D. J. Org. Chem. 2009, 74, 981-988. doi:10.1021/jo802012a

108.Gu, Z.-m.; Zhou, D.; Lewis, N. J.; Wu, J.; Shi, G.; McLaughlin, J. L. Bioorg. Med. Chem. 1997, 5, 1911-1916. doi:10.1016/S0968-0896(97)00129-6

109.D'Souza, L. J.; Sinha, S. C.; Lu, S.-F.; Keinan, E.; Sinha, S. C. Tetrahedron 2001, 57, 5255-5262. doi:10.1016/S0040-4020(01)00381-7

110.Sinha, S. C.; Sinha-Bagchi, A.; Keinan, E. J. Am. Chem. Soc. 1995, 117, 1447-1448. doi:10.1021/ja00109a037

111. Keinan, E.; Sinha, S. C. Pure Appl. Chem. 2002, 74, 93-105. doi:10.1351/pac200274010093

112. Sinha, S. C.; Sinha-Bagchi, A.; Yazbak, A.; Keinan, E. Tetrahedron Lett. 1995, 36, 9257-9260. doi:10.1016/0040-4039(95)02018-K

113.Avedissian, H.; Sinha, S. C.; Yazbak, A.; Sinha, A.; Neogi, P.; Sinha, S. C.; Keinan, E. J. Org. Chem. 2000, 65, 6035-6051. doi:10.1021/jo000500a

114. Chen, Z.; Sinha, S. C. Tetrahedron 2008, 64, 1603-1611. doi:10.1016/j.tet.2007.11.089

115.Sinha, S. C.; Sinha, A.; Yazbak, A.; Keinan, E. J. Org. Chem. 1996, 61, 7640-7641. doi:10.1021/jo961286m 
116. Sinha, S. C.; Sinha, A.; Sinha, S. C.; Keinan, E. J. Am. Chem. Soc. 1998, 120, 4017-4018. doi:10.1021/ja973696d

117.Zeng, L.; Ye, Q.; Oberlies, N. H.; Shi, G.; Gu, Z.-M.; He, K.; McLaughlin, J. L. Nat. Prod. Rep. 1996, 13, 275-306. doi:10.1039/np9961300275

118.Woo, M. H.; Cho, K. Y.; Zhang, Y.; Zeng, L.; Gu, Z.-M.; McLaughlin, J. L. J. Nat. Prod. 1995, 58, 1533-1542. doi:10.1021/np50124a009

119.Zhang, Y.; Zeng, L.; Woo, M.-H.; Gu, Z.-M.; Ye, Q.; Wu, F.-E.; McLaughlin, J. L. Heterocycles 1995, 41, 1743-1755. doi:10.3987/COM-95-7101

120.Wang, Z.-M.; Tian, S.-K.; Shi, M. Tetrahedron Lett. 1999, 40, 977-980. doi:10.1016/S0040-4039(98)02577-5

121.Wang, Z.-M.; Tian, S.-K.; Shi, M. Eur. J. Org. Chem. 2000, 349-356. doi:10.1002/(SICI)1099-0690(200001)2000:2<349::AID-EJOC349>3.0 .CO;2-J

122.Wang, Z.-M.; Tian, S.-K.; Shi, M. Tetrahedron: Asymmetry 1999, 10, 667-670. doi:10.1016/S0957-4166(99)00039-7

123.Wang, Z.-M.; Tian, S.-K.; Shi, M. Chirality 2000, 12, 581-589. doi:10.1002/1520-636X(2000)12:7<581::AID-CHIR6>3.0.CO;2-P

124.Fang, X.-P.; Rupprecht, J. K.; Alkofahi, A.; Hui, Y.-H.; Liu, Y.-M.; Smith, D. L.; Wood, K. V.; McLaughlin, J. L. Heterocycles 1991, 32, 11-17. doi:10.3987/COM-90-5610

125.Evans, P. A.; Cui, J.; Gharpure, S. J.; Polosukhin, A.; Zhang, H.-R. J. Am. Chem. Soc. 2003, 125, 14702-14703. doi:10.1021/ja0384734

126.Zhao, H.; Gorman, J. S. T.; Pagenkopf, B. L. Org. Lett. 2006, 8, 4379-4382. doi:10.1021/ol061847o

127.Wang, J.; Pagenkopf, B. L. Org. Lett. 2007, 9, 3703-3706. doi:10.1021/ol701797e

128.Phillips, G. A.; Wright, T. B.; Stevens, A. C.; Pagenkopf, B. L. Can. J. Chem. 2015, 93, 196-198. doi:10.1139/cjc-2014-0288

129.Phillips, G. A.; Palmer, C.; Stevens, A. C.; Piotrowski, M. L.; Dekruyf, D. S. R.; Pagenkopf, B. L. Tetrahedron Lett. 2015, 56, 6052-6055. doi:10.1016/j.tetlet.2015.09.064

130.Surburg, H.; Panten,, J. Common Fragrance and Flavour Materials: Preparation, Properties and Uses, 5th ed.; Wiley-VCH: Weinheim, 2006. doi:10.1002/3527608214

131.Rychnovsky, S. D.; Bartlett, P. A. J. Am. Chem. Soc. 1981, 103, 3963-3964. doi:10.1021/ja00403a075

132. David, L.; Veschambre, H. Tetrahedron Lett. 1984, 25, 543-546. doi:10.1016/S0040-4039(00)99933-7

133. Méou, A.; Bovanah, N.; Archelas, A.; Zhang, X. M.; Guglielmetti, R.; Furstoss, R. Synthesis 1990, 752-753. doi:10.1055/s-1990-27003

134. Mischitz, M.; Faber, K. Synlett 1996, 978-980. doi:10.1055/s-1996-5638

135.Duan, S.; Moeller, K. D. Org. Lett. 2001, 3, 2685-2688. doi:10.1021/ol0162670

136. Wan, K. K.; Litz, J. P.; Vosberg, D. A. Tetrahedron: Asymmetry 2010, 21, 2425-2428. doi:10.1016/j.tetasy.2010.08.011

137.Al Hazni, A. M.; Sheikh, N. S.; Bataille, C. J. R.; Al-Hadedi, A. A. M.; Watkin, S. V.; Luker, T. J.; Camp, N. P.; Brown, R. C. D. Org. Lett. 2014, 16, 5104-5107. doi:10.1021/ol502454r

138.Suzuki, T.; Suzuki, M.; Furusaki, A.; Matsumoto, T.; Kato, A.; Imanaka, Y.; Kurosawa, E. Tetrahedron Lett. 1985, 26, 1329-1332. doi:10.1016/S0040-4039(00)94885-8

139.Morita, H.; Kishi, E.; Takeya, K.; Itokawa, H.; litaka, Y. Phytochemistry 1993, 34, 765-771. doi:10.1016/0031-9422(93)85356-V

140.Xiong, Z.; Corey, E. J. J. Am. Chem. Soc. 2000, 122, 9328-9329. doi:10.1021/ja0024901
141. Harding, W. W.; Lewis, P. A.; Jacobs, H.; McLean, S.; Reynolds, W. F.; Tay, L.-L.; Yang, J.-P. Tetrahedron Lett. 1995, 36, 9137-9140. doi:10.1016/0040-4039(95)01957-J

142. Morimoto, Y.; Iwai, T.; Kinoshita, T. J. Am. Chem. Soc. 1999, 121, 6792-6797. doi:10.1021/ja990154i

143. Morimoto, Y.; Kinoshita, T.; Iwai, T. Chirality 2002, 14, 578-586. doi:10.1002/chir.10083

144. Hoye, T. R.; Jenkins, S. A. J. Am. Chem. Soc. 1987, 109, 6196-6198. doi:10.1021/ja00254a056

145. Hashimoto, M.; Yanagiya, M.; Shirahama, H. Chem. Lett. 1988, 645-646. doi:10.1246/cl.1988.645

146. Hashimoto, M.; Harigaya, H.; Yanagiya, M.; Shirahama, H. Tetrahedron Lett. 1988, 29, 5947-5948. doi:10.1016/S0040-4039(00)82236-4

147. Hashimoto, M.; Harigaya, H.; Yanagiya, M.; Shirahama, H. J. Org. Chem. 1991, 56, 2299-2311. doi:10.1021/jo00007a013

148. Morimoto, Y.; Iwai, T.; Yoshimura, T.; Kinoshita, T. Bioorg. Med. Chem. Lett. 1998, 8, 2005-2010. doi:10.1016/S0960-894X(98)00347-3

149. Morimoto, Y.; Iwai, T.; Nishikawa, Y.; Kinoshita, T. Tetrahedron: Asymmetry 2002, 13, 2641-2647. doi:10.1016/S0957-4166(02)00718-8

150.Rodríguez-López, J.; Chrisóstomo, F. P.; Ortega, N.; López-Rodríguez, M.; Martín, V. S.; Martín, T. Angew. Chem., Int. Ed. 2013, 52, 3659-3662. doi:10.1002/anie.201209159

151.Morimoto, Y.; Takeuchi, E.; Kambara, H.; Kodama, T.; Tachi, Y.; Nishikawa, K. Org. Lett. 2013, 15, 2966-2969. doi:10.1021/ol401081e

152. Itokawa, H.; Kishi, E.; Morita, H.; Takeya, K.; litaka, Y. Tetrahedron Lett. 1991, 32, 1803-1804. doi:10.1016/S0040-4039(00)74334-6

153. Ujihara, K.; Shirahama, H. Tetrahedron Lett. 1996, 37, 2039-2042. doi:10.1016/0040-4039(96)00212-2

154. Morimoto, Y.; Muragaki, K.; Iwai, T.; Morishita, Y.; Kinoshita, T. Angew. Chem., Int. Ed. 2000, 39, 4082-4084. doi:10.1002/1521-3773(20001117)39:22<4082::AID-ANIE4082>3.0.C $0 ; 2-Z$

155. Sheikh, N. S.; Bataille, C. J.; Luker, T. J.; Brown, R. C. D. Org. Lett. 2010, 12, 2468-2471. doi:10.1021/ol100513y

156. Hioki, H.; Yoshio, S.; Motosue, M.; Oshita, Y.; Nakamura, Y.; Mishima, D.; Furukawa, Y.; Kodama, M.; Ueda, K.; Katsu, T. Org. Lett. 2004, 6, 961-964. doi:10.1021/ol036471i

157.Sakemi, S.; Higa, T.; Jefford, C. W.; Bernadinelli, G. Tetrahedron Lett. 1986, 27, 4287-4290. doi:10.1016/S0040-4039(00)94254-0

158. Hashimoto, M.; Kan, T.; Nozaki, K.; Yanagiya, M.; Shirahama, H.; Matsumoto, T. Tetrahedron Lett. 1988, 29, 1143-1144. doi:10.1016/S0040-4039(00)86672-1

159. Hashimoto, M.; Kan, T.; Nozaki, K.; Yanagiya, M.; Shirahama, H.; Matsumoto, T. J. Org. Chem. 1990, 55, 5088-5107. doi:10.1021/jo00304a022

160. Corey, E. J.; Ha, D.-C. Tetrahedron Lett. 1988, 29, 3171-3174. doi:10.1016/0040-4039(88)85113-X

161. Macherla, V. R.; Liu, J.; Bellows, C.; Teisan, S.; Nicholson, B.; Lam, K. S.; Potts, B. C. M. J. Nat. Prod. 2005, 68, 780-783. doi:10.1021/np049597c

162. Riclea, R.; Dickschat, J. S. Chem. - Eur. J. 2011, 17, 11930-11934 doi:10.1002/chem.201101139

163.Göhler, S.; Roth, S.; Cheng, H.; Göksel, H.; Rupp, A.; Haustedt, L. O.; Stark, C. B. W. Synthesis 2007, 17, 2751-2754. doi:10.1055/s-2007-983797 
164.Adrian, J.; Roth, S.; Stark, C. B. W. ChemCatChem 2016, 8, 1679-1684. doi:10.1002/cctc.201600179

165.Luo, S.-H.; Luo, Q.; Niu, X.-M.; Xie, M.-J.; Zhao, X.; Schneider, B.; Gershenzon, J.; Li, S.-H. Angew. Chem., Int. Ed. 2010, 49 , 4471-4475. doi:10.1002/anie.201000449

166.Luo, S.-H.; Wenig, L.-H.; Xie, M.-J.; Li, X.-N.; Hua, J.; Zhao, X.; Li, S.-H. Org. Lett. 2011, 13, 1864-1867. doi:10.1021/ol200380v 167.Huang, X.; Song, L.; Xu, J.; Zhu, G.; Liu, B. Angew. Chem., Int. Ed. 2013, 52, 952-955. doi:10.1002/anie.201208687

168. Guo, S.; Liu, J.; Ma, D. Angew. Chem., Int. Ed. 2015, 54, 1298-1301. doi:10.1002/anie.201410134

169. Hugelshofer, C. L.; Magauer, T. J. Am. Chem. Soc. 2015, 137, 3807-3810. doi:10.1021/jacs.5b02021

170.Xie, J.; Ma, Y.; Horne, D. A. J. Org. Chem. 2011, 76, 6169-6176. doi:10.1021/jo200899v

\section{License and Terms}

This is an Open Access article under the terms of the Creative Commons Attribution License

(http://creativecommons.org/licenses/by/4.0), which permits unrestricted use, distribution, and reproduction in any medium, provided the original work is properly cited.

The license is subject to the Beilstein Journal of Organic Chemistry terms and conditions:

(http://www.beilstein-journals.org/bjoc)

The definitive version of this article is the electronic one which can be found at: doi:10.3762/bjoc. 12.200 